\title{
The ERA5's Diurnal Cycle of Low-Level Clouds Over Western Central Africa During June-September: Dynamic and Thermodynamic Processes.
}

Atanas Dommo ( $\nabla$ dmmatanas@gmail.com )

University of Yaoundé 1 https://orcid.org/0000-0001-8667-4791

Derbetini A. Vondou

University of Yaoundé 1

Nathalie Philippon

University of Grenoble Alpes

Ryan Eastman

University of Washington

Vincent Moron

Aix Marseille Univ

Noel Aloysius

University of Missouri

\section{Research Article}

Keywords: Low clouds, relative humidity, dynamic, thermodynamic

Posted Date: September 29th, 2021

DOl: https://doi.org/10.21203/rs.3.rs-689885/v1

License: (9) (i) This work is licensed under a Creative Commons Attribution 4.0 International License.

Read Full License 
Title: The ERA5's diurnal cycle of low-level clouds over Western Central Africa during June-September: dynamic and thermodynamic processes.

\author{
A. Dommo \\ Laboratory of Environmental Modeling and Atmospheric Physics, University of Yaoundé 1, \\ Yaoundé, Cameroon, 0000-0001-8667-4791 \\ Derbetini A. Vondou \\ Laboratory of Environmental Modeling and Atmospheric Physics, University of Yaoundé 1, \\ Yaoundé, Cameroon, 0000-0002-8681-5328

\section{N. Philippon} \\ IGE, University of Grenoble Alpes, CNRS, IRD, Grenoble INP, Grenoble, France, 0000- \\ 0003-3519-539X

\section{R. Eastman}

Department of Atmospheric Sciences, University of Washington, Seattle, Washington, 00000001-8696-4211

V. Moron

Aix Marseille Univ, CNRS, IRD, INRAE, Coll. de France, CEREGE, Aix en Provence, France and IRI, Columbia University, Palisades, NY, USA, 0000-0002-4981-9530

\title{
N. Aloysius
}

Department of Natural Resources, University of Missouri, Columbia, Missouri, USA, 00000002-9094-427X

Corresponding author: Atanas DOMMO. Laboratory of Environmental Modelling and Atmospheric Physic (LAMEPA), University of Yaounde 1, Yaoundé, Cameroon Email: dmmatanas@gmail.com

\section{Acknowledgements:}

Authors thank NASA (National Aeronautics and Space Administration) for providing MODIS low clouds data. They also acknowledge the ECMWF for providing reanalysis (ERA5) data. We are also grateful to Andreas Fink and Peter Knippertz for their helpful contributions. 
Abstract

This paper analyzes the diurnal cycle of low cloud cover (LCC) and the atmospheric conditions under which it grows over Western Central Africa during the cloudiest season (June-September). Moderate Resolution Imaging Spectroradiometer (MODIS) observations, Extended Edited Clouds Reports Archive (EECRA) and the fifth generation of reanalysis of the European Centre for Medium Range Weather Forecasts (ECMWF), i.e., ERA5 are used. LCC peaks between 04LT and 07LT and tends to be less dense during the afternoon. The associated dynamic and thermodynamic ERA5 conditions reveal different processes. The strong low level (below $1000 \mathrm{~m}$ ) southwesterly flow in the evening supplies the region with humidity from the ocean and leads to cloud formation. Relative humidity (RH) tendencies show that temperature contributes to $100 \%$ of $\mathrm{RH}$ changes : the strong cooling observed after sunset at 19LT increases RH in the area of about $8 \% / \mathrm{h}$ in the lower layer (below $1000 \mathrm{~m}$ ). The nighttime cooling shows strong cooling rates of about $-1.4 \mathrm{~K} / \mathrm{h}$ after sunset till $22 \mathrm{LT}$, then rates decrease during the night to reach a value of about $-0.3 \mathrm{~K} / \mathrm{h}$ between $22 \mathrm{LT}$ and $07 \mathrm{LT}$. The cloud formation is mostly related to horizontal air advection, strong convergence in the lower layer and turbulent upwards mixing of moisture, while cooling at the cloud-top helps to maintain the cloud deck once it has formed. During daytime, solar radiation suppressed cooling at the cloud-top, thereafter strong turbulent kinetic energy acts to partly destroy the cloud deck and cloud fraction.

keywords: Low clouds, relative humidity, dynamic, thermodynamic

\section{Introduction}

Low level clouds cover large regions of the Earth's surface. Worldwide, low clouds cover (LCC) approximately $28 \%$ of the earth's land surface (Hahn and Warren 2007) and impact earth's surface energy balance (Chen et al. 2000) mostly by decreasing incoming solar radiation at the surface. Low clouds are close to the Earth's surface and therefore exert a relatively small effect on the top of atmosphere outgoing longwave radiation (Stephens and Greenwald 1991; Hartmann et al. 1992). Consequently, LCC produces a strong net cooling at the surface. In general, low clouds form in strong lower tropospheric static stability, in response to either cooling or moistening of the boundary layer (Wood et al. 2012) driven by radiative processes, buoyancy and advection. However, turbulent mixing may be more efficient in many circumstances for generating large scale saturation. Under certain 
conditions, Garratt (1999) shows that the primary source of turbulence may be vertical shear of horizontal wind or buoyancy flux due to exchange of latent heat release from the surface. Paluch and Lenschow (1991) argue that the exchange with the surface is critically dependent upon the buoyancy of the air immediately close to the surface.

The understanding of climatic processes over Central Africa suffers from the unavailability of in situ observations. This holds particularly true for low cloud cover over the region while its misrepresentation in climate models biases temperature and rainfall simulations and projection (Knippertz et al. 2011; Schuster et al. 2013). Most of the studies dedicated to the climate of Central Africa revolve around numerical simulations with the main objectives of evaluating climate models (Mba et al. 2018; Fotso et al. 2016, 2017; Vondou et al. 2017; Sonkoue et al. 2018; Tamoffo et al. 2019a). For instance, Tamoffo et al. (2021) used process-based evaluations to assess the performance of two versions of Rossby Centre Regional Climate Model (RCA4) in simulating rainfall over Congo Basin. The two versions are RCA4 version 1 (RCA4-v1) with strong turbulent mixing and the modified one, RCA4 version 4 (RCA4-v4), with reduced turbulent mixing. These authors show that RCA4-v4 injects less moisture to the free atmosphere, and thus leads to an anomalous moistening of the lower layers and an increasing LCC. This increasing LCC is more pronounced over West Central Africa (WCA) than over the Congo Basin. Consequently, the surface solar radiation is reduced over WCA, then enhances the surface temperature gradient between WCA and the Congo Basin. Dommo et al. (2018) have produced the first assessment of the mean spatiotemporal evolution of LCC over WCA using a set of satellite data, ground-based observation and reanalysis. These authors find that WCA is mostly covered by low stratiform clouds during the June-September (JJAS) dry season and this LCC is particularly important for forest growth (Philippon et al. 2019). Stratiform low clouds are generally observed in coastal areas (Pilié et al. 1979; Cermak 2012) where they sustain vegetation by lowering temperature and bringing substantial amounts of water. These ecosystems may not be present without LCC (Del-Val et al. 2006; Garcia-Santos et al. 2004). In WCA, LCC extends inland up to around $15^{\circ} \mathrm{E}$ then dissipates just westward of the Congo basin leeward of low-level W-SW winds (i.e. westward of Chaillu Mts, Cristal Mts and Batéké plateaus). The coastal plains approximately between Libreville (Gabon) and Pointe Noire (Congo) and the ocean facing valleys have the largest LCC with a maximum intensity at 04 LT (Dommo et al. 2018). Over hills and plateaus, LCC decreases with a maximum intensity at 10LT. The dissipation of LCC east of $15^{\circ} \mathrm{E}$ may be at least partly due to the foehn effect (Dommo et al. 2018). While this recent study helped to underline the diurnal evolution and spatial extension of low clouds in WCA, 
until now, very little attention has been paid to these clouds. In WCA, Dommo et al. (2018) haven't produced an in-depth analysis on cloud controlling mechanisms such as thermodynamic (relative humidity change, radiative cooling, heating at the surface) and dynamic (humidity advection and convergence, turbulence, vertical mixing) that control low cloud formation and dissipation at the diurnal scale. This incompleteness in the study of processes driving LCCs formation, maintenance and dissipation is a crucial limitation for climate studies and modeling in WCA, demanding substantial improvements. In SWA, low level clouds form during the night and persits during the following day (Kalthoff et al 2018). They affect the energy balance at the surface and the diurnal cycle of the atmospheric boundary layer (Knippertz et al. 2011, Hannack et al. 2017). Schrage et al. (2007) showed that cloudy nights in Parakou are characterized by strong moisture convergence at $925 \mathrm{hPa}$ and a low static stability. In SWA, intensifying nocturnal low-level jets (NLLJ) drive cloud formation (Knippertz et al. 2011, Schrage and Fink 2012, Schuster et al. 2013, Babic et al. 2019, Lehou et al. 2020, Alder et al. 2019, Zouzoua et al. 2021). Prior to low- cloud formation, cold air advection -bringing large amounts of humidity- from the sea in addition to strong radiative cooling over land after sunset are the main factors leading to saturation. After formation, the deck is maintained by a well-mixed sub-cloud layer due to vertical shear driven turbulence associated with the intensity of NLLJ. Schuster et al. (2013) shown that in very stable conditions, turbulent energy is dissipated in the area of strong radiative cooling after sunset. Schrage et al. 2007 found that if radiative cooling is anomalously strong, the surface layer can decouple with the lower atmosphere, impeding the cloud formation whereas turbulent fluxes of moisture and heat can support cloud formation depending on vertical stability. Babic et al. (2019a) showed that cooling increases the relative humidity leading to saturation and cloud formation. After sunrise, solar heating at the surface causes positive sensible heat flux and upwards transport of warm air thus deepening the atmospheric boundary layer (ABL) (Babic et al. 2019, Lehou et al. 2020, Alder et al. 2019).

The main objective of this study is to make a more complete description of atmospheric conditions and processes relevant to the diurnal cycle of low clouds in JJAS in WCA (Fig 1), thus deepening the preliminary study of Dommo et al. (2018). We seek to answer the following questions: what the dynamic and thermodynamic conditions under which low clouds grow along the diurnal cycle in WCA during the cloudy dry season (JJAS). Specifically, is turbulence necessary for LCCs formation in WCA ? Up to what degree does turbulence contribute to LCCs formation or dissipation in WCA ? What dominates the relative 
humidity and advection changes during the diurnal cycle ? What surface conditions are relevant to low cloud formation and dissipation? Because of the lack of in situ and aircraft measurements in WCA, our analysis is mostly based on ERA5 reanalysis that provides high spatio-temporal datasets and various atmospheric parameters useful to assess the dynamic and thermodynamic conditions relevant for low-cloud formation and dissipation. The paper is organized as follows: in section 2 we make a brief description of the data used and statistical analysis applied on ground and satellite observations and ERA5. Section 3 includes a brief validation of ERA5 low cloud fraction against satellite and ground observations. In section 4, the diurnal cycle of low cloud cover in ERA5 is assessed. Section 5 depicts the atmospheric conditions relevant to the low cloud cover diurnal cycle and we end in section 6 with a conclusion and discussion.

\section{1) Data}

In this section, we briefly describe and characterize the three cloud products used in this study. The first two are the daily Moderate Resolution Imaging Spectroradiometer (MODIS) Satellite data from National Aeronautic and Space Administration (NASA) and the in-situ observations (Extended Edited Clouds Reports Archive (EECRA) collected from ground-based observations). The last dataset is the fifth generation of reanalysis of the European Centre for Medium Range Weather Forecasts (ECMWF), i.e., ERA5, which is the improved version of ERA Interim. ERA5 reanalysis are used to investigate the atmospheric and thermodynamic conditions under which low clouds grow in WCA, whereas EECRA and satellite observations are used in this study for spatial and diurnal comparisons with ERA5.

The topographic aspects of the study area are displayed in Fig 1. The region is characterized by moderate topographic elevation (Fig 1) with plateaus, coastal plains and valleys. Details about the geographical aspects of the study area can be found in Dommo et al. (2018).

\subsection{Satellite and observational data of low clouds}

\subsubsection{MODIS low clouds cover}

MODIS is a key instrument of NASA's Earth Observing System (EOS) on board Terra and Aqua satellites (Sun et al. 2012). With a sun-synchronous polar orbit nearly perpendicular to the equator, both Terra and Aqua satellites offer a daytime and nighttime view of the 
Earth's surface. Their equator crossing times are 1:30am and 13:30 pm LT for Aqua and 10:30am and 22:30pm LT for Terra. MODIS sensor collects data within 36 spectral bands, ranging from 0.4 micrometer to 14.4 micrometer, and provides images at $250 \mathrm{~m}$ resolution at nadir for two bands, $500 \mathrm{~m}$ resolution for 5 bands and the remaining 29 bands at $1 \mathrm{~km}$. Sixteen of the $1 \mathrm{~km}$ resolution bands cover medium to large infrared wavelengths (3.75-14.2 $\mu \mathrm{m})$. The data used are L3 MODIS daytime, nighttime and daily timescales at $1^{\circ} \times 1^{\circ}$ grid point. The level-3 statistics include mean, minimum, maximum, standard deviation and also fraction of cloudy and clear pixels. In the level-3 dataset, statistics of each $1^{\circ} \times 1^{\circ}$ gridpoint are derived by subsampling and aggregating every fifth of 1-km near-nadir pixel (Oreopoulos, 2005). For this study, both Aqua (MYD08 D3) and Terra (MOD08 D3 $)$ daily mean low cloud fraction for the period 2014-2015 at $1 \mathrm{~km}$ spatial resolution are combined and account for MODIS low clouds. MODIS low clouds cover is obtained by reprocessing the MODIS (https://ladsweb.modaps.eosdis.nasa.gov/archive/allData/61/) day and night cloud mask data using a cloud top temperature (CTT) filter at $0^{\circ} \mathrm{C}$. The filter aims to eliminate all observations with CTT below $0^{\circ} \mathrm{C}$, given that the study area is a warm area. The cloud mask algorithm (Ackman et al. 1988) uses a series of thresholds applied to 20 of the 36 MODIS bands to identify the presence of clouds and give information on individual cloud test results.

\subsubsection{EECRA}

The EECRA data used in this study are ground based observations i.e. the type of cloud is determined by a trained observer, based on cloud base height and physical characteristics (www.atmos.washington.edu/CloudMap/). The land-based EECRA data are from 5388 weather stations on land areas spread over all continents, as well as a few stations on Arctic sea ice. EECRA offers a climatology for the 1971-2009 period of different cloud types within the low, middle and high levels of the atmosphere in addition to cloud base height and present weather conditions. Reports from automated weather stations that do not contain cloud information are not included in EECRA database. Several quality controls were applied on raw reports so that inconsistent reports are excluded. Nighttime observations are screened for adequate lunar illuminance (Hahn et al. 1995) to correct underestimation of clouds due to inadequate nighttime illumination of cloud cover. The dataset includes monthly averages, seasonal, multi-year annual averages as well as 3-hourly reports for eight reporting times per day $(01,04,07,10,13,16,19,22 \mathrm{LT})$. For this study, we use 3-hourly low cloud amount for the period JJAS 1971-2009 over the WCA. Low clouds type (their base height is generally below 600m) are as follows: fog, stratus, stratocumulus, cumulus and 
cumulonimbus; nimbostratus, altocumulus, altostratus for middle clouds and finally cirrostratus, cirrus, cirocumulus, dense cirrus for high clouds. In EECRA, stratocumulus as well as cumulus and cumulo-nimbus are classified as low clouds because their base height is close to the surface despite a larger vertical extension. The number of reports varies considerably. Then, to avoid bias due to missing records, we selected the 18 stations which provide at least $25 \%$ of 3-hourly data during JJAS over the 39-year EECRA span (red triangles on Fig 1). The diurnal cycle is obtained by averaging low clouds amount over each of the eight time steps for JJAS seasons and for the 18 stations.

\subsection{ERA5 data}

Within Copernicus Climate Change Services, the European Centre for Medium-range Weather Forecasts (ECMWF) currently produces the Fifth Generation Reanalysis (ERA5) which includes a detailed record of the global atmosphere, land surface and ocean waves from 1950 to present. This new reanalysis replaces the previous ERA Interim reanalysis that was launched in 2006. ERA5 is based on the 41r2 cycle of the integrated operational forecasting system (IFS) since 2016. In addition to its high horizontal resolution $(31 \mathrm{~km}$, compared to $75 \mathrm{~km}$ for ERA-interim), ERA5 also extends to 137 altitude levels (from the surface to 0.01 hPa, i.e. $80 \mathrm{~km}$ ). ERA5 provides hourly data for a large number of atmospheric and oceanic variables and includes uncertainty information for all variables (Hersbach et al. 2018). The IFS relied on a number of prescribed radiation forcings and ocean surface conditions. Based on the number of parameters (https://confluence.ecmwf.int/display/CKB/ERA5+data+documentation) and many new or reprocessed observations, ERA5 is appropriate for climate study (Lei et al. 2020). The use of ERA5 has many advantages: 1) it offers data at the high spatiotemporal resolution which is suitable for regions lacking in situ observation, 2) it offers a wide range of parameters that allow for in-depth study of dynamic and thermodynamic conditions. In addition to different atmospheric parameters provided by ERA5, it also provides cloud variables in 2-D and 3-D dimensions. For our present study, we used hourly data on their native spatial resolution $(31 \mathrm{~km} \times 31 \mathrm{~km})$ for the period 2014-2015. Due to limited computational resources, only two years are chosen for thermodynamic and dynamic analyses. Considering land only pixels over the interested area, the representativeness of the two selected years is checked by computing the diurnal cycle of low clouds fraction for each of the years 1979-2019 (Fig 2).

Both years 2014 and 2015 are cloudier than normal. The amplitude of the diurnal cycle is almost constant from one year to the other, so the analysis of the diurnal cycle of the above- 
mentioned years is a good approximation of what may happen on average over WCA. For our present study, low level cloud fraction (3-D and 2-D), total column water vapor and total column liquid water content are extracted for low cloud characteristics. Also, wind (horizontal and vertical components), temperature, relative and specific humidity, cloud liquid water content, net shortwave and longwave radiation, surface latent and sensible heat are used for dynamic and thermodynamic processes. In addition, vertical profiles of moisture convergence and advection, relative humidity changes, cooling and the main contribution to horizontal advection are investigated.

\section{3) ERA5 evaluation against MODIS and EECRA}

Here we compare the mean spatial distribution as well as the diurnal evolution of LCC fraction in ERA5 during JJAS season with MODIS and EECRA over WCA. This will reveal the capability of ERA5 to capture the spatial distribution as well as the diurnal cycle of LCC in WCA. We focus our analysis on the land area $6^{\circ} \mathrm{S}-5^{\circ} \mathrm{N}$ and $8^{\circ} \mathrm{E}-15^{\circ} \mathrm{E}$ (Fig 1). The LCC spatial distribution is controlled by topography and a rapid decrease in cloud amount is observed eastward from $15^{\circ} \mathrm{E}$, corresponding to the downward slopes facing toward the Congo basin (Dommo et al. 2018).

\section{1) Mean seasonal pattern}

Fig 3 displays the mean frequency of LCC over WCA using Terra and Aqua MODIS (hereafter, MODIS) data (Fig 3a), ERA5 reanalysis (Fig 3b) and EECRA (Fig 3c) both for nighttime and daytime. Fig 3d displays the mean diurnal cycle of EECRA stations and the corresponding ERA5 pixels. Also presented in Fig 3 are the spatial averages of four gridpoints representing MODIS cloud amount for each crossing time as stated in section 2.1.1. All three products show a local cloud maxima greater than $80 \%$ along the Atlantic coast, namely the Cameroonian Coast, Gabon, and almost all of SW Congo, west of Brazzaville (Fig 1). There are some substantial differences between the spatial distribution of the three products: both MODIS and EECRA (Fig 3a \& 3c) show LCC fraction $>=65 \%$ in almost all parts of our box area whereas ERA5 (Fig 3b) struggles to represent low clouds in south East Cameroon and eastern Gabon (their amounts are not greater than 50\%). To make comparable estimates with EECRA data, the diurnal cycle is computed by averaging for each time step only the 18 ERA5 pixels close to the EECRA stations (Fig 1). Fig 3d displays the mean diurnal cycle of low-level clouds from EECRA stations and for the corresponding ERA5 and MODIS pixels. Diurnal cycles of low clouds from EECRA and ERA5 are largely in phase 
263

264

265

266

267

268

269

270

271

272

273

274

275

276

277

278

279

280

281

282

283

284

285

286

287

288

289

290

291

292

293

294

despite some discrepancy from late afternoon to early night. Diurnal cycle amplitude of EECRA is about $15 \%$ compared to $35 \%$ for ERA5 and $24 \%$ for MODIS. The differences among the two products along the diurnal cycle and for each pixel/station are the largest $(>20 \%)$ in the early night, however this difference decreases from late night (about 10\%) to late morning at 10LT (about 4\%).

In term of amounts, EECRA shows a maximum cloud amount of about $80 \%$ at 04 LT and a minimum of about $65 \%$ at 22 LT. This maximum remains constant until 10LT. ERA5 shows a maximum (minimum) cloud amount of about 80\% (40\%) at 10 LT (19 LT) whereas MODIS shows a maximum (minimum) of about $94 \%(70 \%)$ at $10.30 \mathrm{am}(22.30 \mathrm{pm})$. MODIS may have a tendency to overestimate cloud amounts compared to EECRA observations. This is because MODIS clouds are observed from all parts of the MODIS swath, including near edges where the wide sensor view angle biases cloud amount (Maddux et al. 2010).

\section{2) Diurnal evolution of the spatial pattern}

To compare spatial evolution of ERA5 LCC with that of EECRA along the diurnal cycle, only eight time slots $(01,04,07,10,13,16,19,22 \mathrm{LT})$ are retained for ERA5 analyses. The spatial evolution of LCCs cover along the diurnal cycle as observed in ERA5 is represented in Fig 4a. LCC begins forming in the first half of the night at about 22 LT in the high-elevation areas of south Cameroon. Clouds spread progressively along the Gabon coast and continue to grow during the course of the night so that at 07 LT LCCs cover the majority of the area. From 01 LT to 07 LT, LCCs are mostly confined along the west facing slopes with a maximum cloud cover reaching $95 \%$. At 10LT, a north-south gradient of cloud cover is observable. Low clouds start dissipating in south Cameroon and Equatorial Guinea whereas the LCC cover increases in the coastal plains and west facing slopes of Gabon and the SW Republic of Congo, with frequency above $90 \%$ until 16 LT. At 16 LT, clouds begin significantly dissipating, even if substantial amounts (55 60\%) are still seen at 19LT. Fig 4b shows the three hourly spatial distribution of LCCs as observed in EECRA stations. The observed spatial distribution shows that during the diurnal cycle, EECRA low cloud amounts are generally greater than $50 \%$ in almost all parts of the green box, except for a few stations in SW Congo republic at 01LT and 22LT showing amounts between 40 and 50\%. Also observed in Fig $\mathbf{4 b}$ is the north-south dissipation of low clouds from 16LT to 22LT. All these features are also observed in ERA5 even if there are some differences between the two products during the diurnal cycle. For instance, from $10 \mathrm{LT}$, LCCs diminish for coastal 
EECRA stations (Fig 4b) while it is not observed in ERA5, but the frequency stays over 60\% in EECRA. Furthermore, LCCs in EECRA are always present over south west Gabon with a maximum cloud cover greater than $90 \%$, whereas in ERA5 amounts are barely above $70 \%$ in this area between 19LT and 22LT.

Despite an underestimation of low clouds by ERA5 with respect to spatial frequencies and throughout the diurnal cycle, ERA5 does show reasonable agreement with ground-based observations. The spatial pattern of LCCs in ERA5 also matches well with CALIOP and SAFNWC retrievals (see Fig 2a,b in Dommo et al. 2018). The LCCs underestimation in ERA5 is likely due to the weakly incorporated land assimilation system, combining in-situ and satellite observations (Hersbach et al. 2018). The relative agreement between satellite observations and ERA5 low level clouds has already been drawn in West Africa (Danso et al. 2019) and over Tibetan plateau and eastern China (Lei et al. 2020). So, because of ERA5 improved spatial/temporal resolution, the following analysis will be made using ERA5 variables to picture out low-level cloud diurnal cycle characteristics and thermodynamic processes.

Clouds form when air becomes saturated with respect to liquid water. Under certain conditions, water vapor condenses into some atmospheric particles to form clouds. Then, time series of total column cloud liquid water content (LWP hereafter) together with total column water vapor (TWV) are shown in Fig 4c. The diurnal cycle of TWV varies very much slightly. The minimum of LWP is observed at 21LT. Thereafter and during the course of the night, there is an increase of LWP with a first maximum observed at 05LT then a second one at 10LT, probably in links with clouds thickening and spreading over the region. During daytime, LWP decreases strongly (together with LCCs dissipation) to reach its daily minimum. The features observed in this figure suggest that different atmospheric mechanisms are at play to explain the LCCs diurnal cycle. These aspects are explored in the following section. In the following analyses, only land pixels are considered within the green box in Fig 4a as processes driving low clouds may be different on land and on sea. To account only for the cloudiest areas, only land pixels within the green box which recorded on average at least $80 \%$ of low clouds at $07 \mathrm{LT}$ are considered. This threshold also enables to reduce biases due to spatial heterogeneity as the processes driving low cloud cover may be different over the coast, windward slopes and plateaus.

\section{4) Atmospheric conditions associated with the diurnal cycle of LCCs}


In this section, we document the evolution of dynamic (wind, advection, turbulence) and thermodynamic (radiative cooling, moisture) parameters during the diurnal cycle. The aim is to analyze their relationships with LCC. It has been shown in SWA that moisture (Babic et al 2019a) needed for saturation, and strong low level wind speed (Knippertz et al. 2011, Schuster et al. 2013) driving vertical mixing, are important factors for stratus formation. Do the core of those dynamic and thermodynamic parameters co-located with large LLCs also be observed in WCA ? We then investigate the atmospheric conditions driving low clouds by analyzing the evolution of wind speed and relative humidity $(\mathrm{RH})$. The moisture flux (advection) and divergence are also investigated in this section. This is important to evaluate the behaviour (inflow or outflow) of moisture within the study area and the link with LCC formation and dissipation. Turbulence driven by nocturnal low-level jets has been proposed as an important factor for low cloud formation in SWA (Knippertz et al. 2011) through its contribution to vertical mixing. Therefore, we also analyze in this section the diurnal cycle of turbulent kinetic energy (TKE). All the computations are done from ground level (pressure < $1000 \mathrm{hPa}$ ) to avoid influences of surface roughness.

\section{1) Thermodynamic and dynamic conditions}

We start the evaluation of atmospheric conditions relevant to low clouds by showing in Fig 5 the JJAS average of three-hourly time-height sections of horizontal wind direction (vectors) and horizontal wind speed (contour) together with relative humidity (RH, shaded). Southwesterly flow up to $1200 \mathrm{~m}$ (Fig 5) features the investigating area. Between 1200m and $2000 \mathrm{~m}$, a minimum in wind speed (about 2m/s) corresponds to the veering from southwesterly to easterly. Above $2000 \mathrm{~m}$, easterlies reach $6 \mathrm{~m} / \mathrm{s}$. Below $1000 \mathrm{~m}$, the maximum wind speed is observed between 22 LT and 04 LT (Fig 5). After 10LT, there is a decrease in RH simultaneously with a decrease in wind speed which starts to increase again in the evening (19 LT).

Three-hourly vertical profiles of cloud fraction averaged over $6^{\circ} \mathrm{S}-5^{\circ} \mathrm{N} / 8^{\circ} \mathrm{E}-15^{\circ} \mathrm{E}$ are provided in Fig 6, along with vertical profiles of specific humidity, moisture advection, divergence of moisture advection, turbulent kinetic energy and static stability. The horizontal moisture advection is computed as follows : $Q_{a d v}=q w$ where $q$ is the specific humidity ( $g . \mathrm{kg}^{-1}$ ) and $w$ is the sum of zonal $(u)$ and meridional $(v)$ wind components all are expressed in meters per second. The diurnal cycle of vertical profile of the low cloud cover (Fig 6) is in phase with Fig 4 but differs in amount because low clouds are 3-D (Fig 6) and 2-D (Fig 4) as 
mentioned in section 2.2. The maximum of low clouds is situated at about $800 \mathrm{~m}$ of altitude at 07 LT whereas the minimum in low clouds is observed at about $1500 \mathrm{~m}$ of altitude at 19LT. The cloud deck height increases from $1000 \mathrm{~m}$ at $10 \mathrm{LT}$ to reach $1500 \mathrm{~m}$ at $16 \mathrm{LT}$ in response to an increase of the Atmospheric Boundary Layer (ABL) depth (not shown) due to entrainment and thermal expansion. Although the specific humidity stays rather constant, less than $16 \mathrm{~g} / \mathrm{kg}$ (Fig 6b) in the lower layers, low level moisture advection (Fig 6c) seems to play a substantial role in cloud occurrence. Positive (negative) advection denotes flow driven by southwesterly wind (easterly wind). Indeed, during the course of the night, advection supplies the area with moisture from the nearby Atlantic (Pokam et al. 2014), which enhances radiative cooling and cloud formation. This occurs despite the temporal mismatch between the height and time of occurrence of the largest cloud fraction and those of moisture advection. Maximum moisture advection observed between 22LT and 04LT - recorded at about $900 \mathrm{~m}$ height - is associated with strong horizontal wind (Fig 5), whereas the largest cloud fraction is observed at about 800m between 07LT and 10LT (Fig 6a). From the early afternoon to the evening, advection is weak due to reduced southwesterlies, and simultaneously, low clouds are partly dissipating. Above $1500 \mathrm{~m}$, easterly flow is the main driver of advection. In order to quantify the inflow or outflow moisture across our interested area, we calculate the divergence of the moisture

\section{expressed by}

$$
\nabla Q_{a d v}=\frac{d Q_{\alpha}}{d x}+\frac{d Q_{\beta}}{d y}
$$
where $Q_{\alpha}$ and $Q_{\beta}$ are the zonal and meridional advections, respectively. When computing moisture divergence with equation 1 , negative (positive) values represent convergence (divergence). Fig 6d shows a strong moisture flux convergence in the low levels $(<600 \mathrm{~m})$ from 22LT to 04LT. Therefore, from the evening to late night, southwesterly (i.e. positive) inflow of moist air below $600 \mathrm{~m}$ is prior to the occurrence of low clouds. Above $1500 \mathrm{~m}$, easterly flow acts to dry the upper layer (Kuete et al. 2019) since the air is drier over the Congo basin than over WCA at $700 \mathrm{hPa}$ in JJAS (not shown). Moreover, moisture divergence is already present in layers between $700 \mathrm{~m}$ and 900m (before the maximum advection) from 22LT and 07LT (Fig 6d). The diurnal cycles of the vertical profile of turbulent kinetic energy (TKE) and static stability are now analyzed. In West Africa (Knippertz et al. 2011, Schrage and Fink. 2012, Babic et al. 2019b) turbulent mixing driven by vertical wind shear plays an important role in stratus formation. At 19LT mixing at the surface is suppressed - as shown by low TKE value $\left(<0.1 \mathrm{~m}^{2} . \mathrm{s}^{-2}\right)($ Fig 6e) - by strong static stability (Fig 6f). Note that positive (negative) values of static stability denote stable (unstable) atmosphere. Thereafter stability decreases during the night due to decrease in cooling (see section 4.3), leading to the moderate increase of TKE from 01LT to 04LT until 
393

394

395

396

397

398

399

400

401

402

403

404

405

406

407

408

409

410

411

412

413

414

415

416

417

418

419

420

421

422

423

424

sunrise (07LT). This induces buoyancy of the moist air and vertical mixing in the lower layers from the radiatively cooled surface (shown below) and contributes to LCCs formation during late night. During daytime, especially in the early afternoon (13LT), TKE is the strongest ( $0.8 \mathrm{~m}^{2} \cdot \mathrm{s}^{-2}$ ) leading to strong instability (Fig 6e). As a result, the cloud deck lifts simultaneously with the LCC dissolution. Thus, depending on its intensity, turbulence contributes to low cloud formation during the night and dissipation during the day along the diurnal cycle in WCA.

The time-height evolution of RH in Fig $\mathbf{5}$ shows large values $>95 \%$ below 1000m with a maximum greater than $95 \%$ between 04LT and 07LT when low level winds are slowing down. Near the surface, the moisture ratio is fairly close to saturation. Indeed, where RH is greater than $80 \%$, if such an air parcel is lifted, the pressure will decrease, and it will cool. The time series of specific humidity (Fig $\mathbf{6 g}$ ), RH (black line) and temperature (red line) (Fig 6h) at 790m (i.e 925hPa) where low clouds peak 07LT, are represented. Simultaneously with the increase in $\mathrm{RH}$ from $94 \%$ to $98 \%$ between 01LT and 07LT, the specific humidity and temperature respectively show a decrease of about $0.2 \mathrm{~g} / \mathrm{kg}$ and $0.5^{\circ} \mathrm{C}$ (the $\mathrm{T}^{\circ}$ reaches its minimum, about $19^{\circ} \mathrm{C}$ at $07 \mathrm{LT}$ ). From 07LT, RH drops from $98 \%$ and reaches its minimum of about $80 \%$ in the late afternoon, due to the diurnal warming since 07LT and T reaches its maximum $\left(\sim 22^{\circ} \mathrm{C}\right)$ at $16 \mathrm{LT}$. In the meantime, specific humidity continues to decrease to reach its minimum (about $14 \mathrm{~g} / \mathrm{kg}$ ) at $13 \mathrm{LT}$. This suggests a moderate drying of the air mass over WCA during daytime. This is accompanied by a significant reduction in cloud cover and an increase in the cloud deck height (Fig 6a). Thereafter, RH starts to increase simultaneously with the increase in specific humidity until 01LT while temperature has been decreasing since 16LT. After sunrise, wind speed drops (Fig 6i) due to strong turbulence (Fig 6e) compared to nighttime where the atmosphere is stabilized (Fig $\mathbf{6 f}$ ) by a cooled surface.

With the aim to investigate the degree of dependency between moisture advection /divergence and LCCs fraction, scatter-plots are computed between 1) LCCs anomaly and moisture advection at $925 \mathrm{hPa}$ (i.e $790 \mathrm{~m}$ above the ground) where the low clouds fraction seems to peak, and 2) between LCCs anomaly and moisture flux divergence at $950 \mathrm{hPa}$ (i.e $550 \mathrm{~m}$ ) where moisture convergence (Fig 6d) seems to be at its maximum. The LCCs anomaly is computed following two steps: firstly, the spatial average considering only the most overcasted pixels (cf Fig 4a) is performed to obtain LCCs hourly time series. Secondly, the anomaly is computed by subtracting from each value of the time series the hourly mean of the 
1952 values (122 days x 8 time slots x 2 years) of LCC time series. Results are presented respectively in Fig 7 and Fig 8.

Correlation coefficient (CC) between LCC anomaly (referred to as "M") and advection at 925 $\mathrm{hPa}$ (Fig 7) increases from 0.31 at 19LT to 0.39 (maximum value) at 01LT simultaneously with an increase in advection (Adv) as shown in Fig 6c. At the same time, LCC anomaly switches from a negative value $(\mathrm{M}=-11 \%)$ at $19 \mathrm{LT}$ to a positive value at 01LT $(\mathrm{M}=2 \%)$. From 01LT to 07LT, $\mathrm{M}$ is positive and is increasing to peak at 07LT $(\mathrm{M}=21 \%)$, fingerprinting an expansion in LCC. During daytime, $\mathrm{M}$ decreases from 3\% at 10LT to reach its minimum of $13 \%$ at 16LT. At $950 \mathrm{hPa}$ (Fig 8) there is strong moisture convergence along the diurnal cycle compared to $925 \mathrm{hPa}$ (level of cloud maximum) where divergence has already taken place (Fig 6d) between 01LT and 07LT. Conversely, the largest LCC anomaly at 07LT is weaker at $950 \mathrm{hPa}$ (Fig 8) compared to $925 \mathrm{hPa}$ (Fig 7). This suggests that near surface moisture is transported to the upper level to reach saturation.

\section{2) Main contributors to moisture advection}

We show in the previous section (Fig 6c) that advection supplies the area in moisture that is necessary for LCCs formation. The moisture advection is computed as $Q_{a d v}=q w$. Then, the changes in moisture advection are the result of horizontal wind (w) and/or specific humidity (q) changes. This means that moisture advection increases (decreases) due to increases (decreases) in specific humidity and/or increases (decreases) in wind speed. In order to quantify whether $\mathrm{q}$ or $\mathrm{w}$ is the main contributor to moisture advection, the advection changes or tendencies are computed. In the following steps, we applied partial derivation to

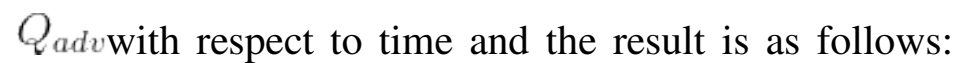

$$
\underbrace{\frac{\partial Q_{a d v}}{\partial t}}_{I}=\underbrace{q \frac{\partial w}{\partial t}}_{I I}+\underbrace{w \frac{\partial q}{\partial t}}_{I I I}
$$
where the term I is the moisture advection changes, the term II is the wind contribution and the term III is moisture contribution to total changes. To compute tendencies, we have applied the serial development of Taylor at any given time $t_{i}$. The results are shown in Fig 9. Note that at time $\mathrm{t}$ in Fig 9, one should understand the plot as the decrease or increase of moisture advection with respect to time t-1. For example, strong positive values at 19LT do not mean that moisture advection is stronger at 19LT than 07LT, but instead higher at 19LT with respect to $16 \mathrm{LT}$ (the prior time step). We see that whatever the time-slot, changes in moisture advection are primarily due to horizontal wind advection. The contribution of specific 
455

456

457

458

459

460

461

462

463

464

465

466

467

468

469

470

471

472

473

474

475

476

477

478

479

480

481

humidity remains close to zero throughout the diurnal cycle. Whether they are positive or negative, the three-hourly variations in advection change below $500 \mathrm{~m}$ are quite small. This is probably due to weak wind speed (less than $5 \mathrm{~m} \cdot \mathrm{s}^{-1}$ ) in the lower layer. In Fig 10, contributions of zonal and meridional flows to moisture advection are drawn. As the contribution of specific humidity is close to zero $\left(w \frac{\partial q}{\partial t} \approx 0\right)$, equation 2 can be rewritten as follows : $\underbrace{\frac{\partial Q_{a d v}}{\partial t}}_{I} \approx \underbrace{q \frac{\partial u}{\partial t}}_{I I}+\underbrace{q \frac{\partial v}{\partial t}}_{I I I}$

where term II and III are respectively the zonal and meridional contributions to advection changes. We observed that the second part of the night is characterized by a small decrease in zonal and meridional advection below $500 \mathrm{~m}$. The largest changes in advection (zonal and meridional) are observed below 1500m and switch from negative (advection decrease) in the morning to positive (advection increase) in the evening. During the course of the diurnal cycle, whether the variability is negative or positive, changes in advection are mainly related to zonal advection change.

\subsection{Relative humidity changes and cooling}

Here, we analyze the changes in relative humidity simultaneously with radiative cooling. Note that cooling rate is expressed as the temporal variation of potential temperature $(\theta)$. Changes in relative humidity $(\mathrm{RH})$ are the result of changes in specific humidity $(\mathrm{q})$ and temperature (T). In order to quantify which of q or $\mathrm{T}$ have the strongest contribution to $\mathrm{RH}$ changes and consequently to low level cloud formation, vertical profiles of their respective contribution are computed using ERA5 reanalysis. Assuming that relative humidity is expressed by $R H=e / e_{s}$ where $e$ is water vapor pressure and $e_{s}$ is the saturated water vapor pressure. Note that $e_{s}$ is a function of temperature and is obtained according to Clausius

Clapeyron relation $\frac{\partial e_{s}}{\partial T}=\frac{L_{v} e_{s}}{R_{v} T^{2}}$ and water vapor pressure is expressed according to $e=\frac{q}{0.378 q+0.622} P$

In these expressions, $\mathrm{T}$ is the air temperature (in kelvin), $\mathrm{P}$ is air pressure (in $\mathrm{hPa}$ ), $\mathrm{Lv}$ is the latent heat of vaporization $\left(2.5 .10^{6} \mathrm{~J}_{\mathrm{kg}}^{-1}\right.$ ) and $R_{v}=461.5 \mathrm{~J} \mathrm{~kg}^{-1} \mathrm{~K}^{-1}$ is the gas constant of water vapor. Given the expression of RH, the contribution of T and q to RH changes is given (Babi'c et al. 2019a, Hannak et al. 2016) by equation 
482

483

484

485

486

487

488

489

490

491

492

493

494

495

496

497

498

499

500

501

502

503

504

505

506

507

508

509

510

511

512

$\underbrace{\frac{\partial R H}{\partial t}}_{I}=\underbrace{\frac{P}{e_{s}} \frac{0.622}{(0.378 q+0.622)^{2}} \frac{\partial q}{\partial t}}_{I I} \underbrace{-\frac{P}{e_{s}} \frac{q L_{v}}{(0.378 q+0.622) R_{v} T^{2}} \frac{\partial T}{\partial t}}_{I I I}$

where term I is the total RH changes, term II is q contribution and term III is T contribution. Because of the minus sign before term III, a positive (negative) value of that term signifies cooling (heating). The calculation of tendencies is performed only from late evening to early morning to emphasize cloud formation (i.e 19LT to 07LT). Results are presented in Fig 11. During the course of the night, there is an increase in RH but the rate of increase is quite different across the three-hourly timestep. In the early evening (at 19LT), there is a strong increase in RH below $500 \mathrm{~m}$ with a maximum of about $+7 \% / \mathrm{h}$, though the increasing tendency decreases with height. During the course of the night, the increasing rate of $\mathrm{RH}$ gradually decreases in the lower layer and reaches about $+3 \% / \mathrm{h}$ at $07 \mathrm{LT}$. But the reverse is observed above $1500 \mathrm{~m}$ where RH increases during the night. Above $1500 \mathrm{~m}$, the contribution of q to $\mathrm{RH}$ changes is more pronounced. On average (Fig 11f) and during almost all the night, cooling contributes $100 \%$ to RH changes (Fig 11f) in the lower layer with an average cooling rate of about $0.6 \mathrm{~K} / \mathrm{h}$ (Fig 11g), even though small contribution of specific humidity (about 5\%) is noticeable at 19LT below 500m. The observed nighttime evolution of cooling (Fig 11g) shows a strong cooling rate (about $-1.3 \mathrm{~K} / \mathrm{h}$ ) in the early evening probably due to rapid thermal inversion over land after sunset coinciding with the increase in moisture advection (Fig 9 \& Fig 10). Note that the increase (decrease) of cooling rate expresses the increase (decrease) in cooling. This cooling gradually decreases during the course of the night and reaches $-0.3 \mathrm{~K} / \mathrm{h}$ at 07LT when the low cloud cover is at its maximum (Fig 6a).

\section{4) Surface energy and radiative balance}

Because low clouds are mostly confined in the boundary layer, which is frequently thermodynamically connected to Earth's surface, our understanding of cloud formation also demands the understanding of surface processes. Energy release from the surface in response to solar radiation is the primary source of vertical motion or convective instability (Wood 2012). Wood (2012) shows that the diurnal cycle of stratocumulus (Sc) clouds is strongly modulated by the diurnal cycle of solar radiation. The maximum of surface net shortwave radiation (Fig 12a, black line) reaches up to $450 \mathrm{~W} \cdot \mathrm{m}^{-2}$ at $13 \mathrm{LT}$ with an interquartile range of about $77 \mathrm{~W} \cdot \mathrm{m}^{-2}$. This is probably due to day-to-day variability of the transparency of the atmosphere. The surface net longwave radiation $\left(R_{L}\right)$ is negative and shows much less variability. Note that net shortwave radiation $\left(R_{S}\right)$ denotes the amount of solar radiation 
513 minus the amount reflected (or albedo) by the earth's surface whereas $R_{L}$ is the difference between the downward and upward thermal radiation at the earth's surface and net radiation ( $\left.\mathrm{R}^{*}\right)$ is the sum of $R_{L}$ and $R_{S}$. At 13LT, $R_{S}$ enhances the latent heat (Fig 12b, red line) which then leads to a large evaporation (Fig 12c). At this time, cloud fraction is decreasing and $\mathrm{R}^{*}=403 \mathrm{~W} \cdot \mathrm{m}^{-2}$. At sunset $(19 \mathrm{LT})$, sensible heat becomes positive $\left(\sim+10.7 \mathrm{~W} \cdot \mathrm{m}^{-2}\right)$. It reaches a value of about $+3 \mathrm{~W} \cdot \mathrm{m}^{-2}$ at 01LT. At the same time, $\mathrm{R} *$ becomes negative and remains so during the night. It varies from $-28 \mathrm{~W} \cdot \mathrm{m}^{-2}$ at $19 \mathrm{LT}$ to $-26 \mathrm{~W} \cdot \mathrm{m}^{-2}$ at $01 \mathrm{LT}$. Then, by contributing to the compensation of negative $R^{*}$ (Fig 12a) from sunset to late night (01LT), downward sensible heat contributes to the development of a stable nocturnal surface layer and the enhancement of wind speed.

A conceptual model summarizing the processes of low cloud formation and dissipation along the diurnal cycle for WCA is proposed in Fig 13, showing evening (19, 22 LT), late night $(01,04,07 \mathrm{LT})$ and daytime $(10,13,16 \mathrm{LT})$ processes. In the evening, the horizontal advection of cool and moist air from the nearby Atlantic by the low level southwesterlies associated with strong moisture convergence of about $14 \mathrm{~s}^{-1} \mathrm{~g} \cdot \mathrm{kg}^{-1}$ leads to a strong radiative cooling of about $-1.4 \mathrm{~K} / \mathrm{h}$ below $500 \mathrm{~m}$ which suppressed mixing. Consequently, there is no clouds formation. The horizontal wind speed is faster with a maximum value of about $4 \mathrm{~m} \cdot \mathrm{s}^{-1}$ simultaneously with the downward sensible heat which contributes to the stabilizing of the near surface layer.

During the late night, wind speed weakens. Then, moisture convergence also weakens as advection decreases, leading to decrease in cooling. As the cloud deck is formed, the cooling weakens at the surface (Fig 11g), and the TKE moderately increases up to $0.4 \mathrm{~m}^{2} . \mathrm{s}^{-2}$ favoring vertical mixing and maintaining the cloud deck. This is in agreement with the study by Schrage and Fink (2012), supporting that vertical transport of moisture contributes to cloud formation. After the cloud deck is formed, an increase of cooling at its top (i.e above $1000 \mathrm{~m}$, see Fig 11g) contributes to stabilizing as it is partly compensated by latent heating. Indeed, the level at which cloud fraction is maximum coincides with the level of strong moisture divergence (Fig 6d). Then, it seems like there is a competition between outflow of moisture and the turbulent vertical transport of moisture. We hypothesize that the altitude at which clouds form is first emptied partially of its moisture, leaving space for well mixed moisture from the lower layers which then condensates to form clouds. 
During daytime, solar radiation heats the cloud top. Consequently, cooling at the top is suppressed and cloud droplets evaporate. This reduces the cloud's thickness then leads to their dissipation. Below the cloud deck, strong turbulence $\left(>0.4 \mathrm{~m}^{2} \cdot \mathrm{s}^{-2}\right)$ which is accompanied by the largest $\mathrm{R}^{*}\left(\sim 403 \mathrm{~W} \cdot \mathrm{m}^{-2}\right)$ acts also to destroy the clouds layer. At the same time, wind speed is the weakest, the cloud layer rises and is less compact.

\section{5) Conclusion and discussion}

The aim of this study is to establish a picture of the dynamic and thermodynamic processes under which LCCs grow in WCA across the diurnal cycle during the JJAS cloudy main dry season. Our analysis is based mostly on ERA5 reanalysis. Before any use of ERA5 data, a short validation with satellite (Terra and Aqua MODIS) and ground-based observations (EECRA) is made in order to show the capability of ERA5 to represent the diurnal cycle and spatial distribution of LCCs. Three-hourly spatial evolution of LCCs from ERA5 and EECRA in addition to LWP and TWV are drawn. We also explored the dynamic and thermodynamic conditions by analysing $\mathrm{RH}$, wind speed, temperature, and specific humidity. In addition, horizontal advection, cooling, convergence and static stability are also computed to strengthen our analysis. The main findings of our study are as follows:

1) Despite an underestimation of LCCs by ERA5, it captures well the mean spatial distribution of low clouds as compared to EECRA and MODIS observations. The LCCs diurnal cycles in EECRA and ERA5 are also well correlated although ERA5 struggles to produce enough clouds during the afternoon. The spatial evolution during the diurnal cycle shows that LCCs fraction is the weakest at 19LT. Then, it starts to grow at 22LT from south-Cameroon. LCCs fraction peaks during late night (04-07 LT) over windward slopes and coastal plains. After sunrise at 07LT, LCCs display a north-south gradient (more LCCs over Gabon than Cameroon) which vanishes as LCCs cover diminishes overall till 19LT. Accordingly, the cloud liquid water content shows similar evolution along the diurnal cycle.

2) WCA is subject in JJAS to a southwesterly flow in the low layers, a flow whose intensity increases from the evening to $01 \mathrm{LT}$ and advects humidity from the ocean to the region. As shown in Fig 5, the large humidity content in the low layers in late night is necessary for condensation and LCCs formation. There is strong moisture convergence in the lower layer $(<500 \mathrm{~m})$ while strong moisture advection is recorded from 19LT to $01 \mathrm{LT}$ at $900 \mathrm{~m}$ of altitude. 
3) We calculated the contributions of specific humidity and also zonal and meridional wind to humidity advection. During the diurnal cycle, advection changes are mostly due to change in horizontal wind, with zonal wind acting as the main driver of these changes as compared to meridional wind. The contribution of specific humidity is quasi close to zero and does not contribute to advection changes.

4) We have also investigated the contributions of temperature and specific humidity to RH changes from the evening to early morning, i.e during clouds formation. The first insight shows that temperature contributes nearly $100 \%$ to RH changes. From 19LT, the strong radiative cooling at the surface increases relative humidity by about $8 \%$ near the surface. During the course of the night, RH gradually increases. Conversely, while below $1000 \mathrm{~m}$ the rate of RH changes is decreasing, the contrary is observed above $1000 \mathrm{~m}$. Changes in RH are mostly due to variations in cooling.

5) While horizontal advection of moisture is shown to be a precondition to LCCs formation, another process is necessary for cloud formation. Vertical upward mixing of moisture from the lower layer during nighttime due to moderate TKE is necessary for cloud formation. This vertical mixing is important for saturation. Once the cloud deck is formed in stable condition, cooling weakens at the surface, strong cooling at the top of the cloud deck is partially compensated by latent heat. All these processes help to maintain the cloud deck. During daytime, low clouds dissipate in response to strong thermodynamic instability due to the increase of solar radiation.

6) Finally, we can conclude that, the LCCs in WCA are formed owing to the combination of the horizontal advection of cooler air, turbulent vertical mixing of moisture. Radiative cooling at the top helps to maintain the cloud deck once it has formed. The dissipation of LCCs is mainly due to strong turbulence.

The use of ERA5 may lead to slight discrepancies when calculating some quantities. For instance, the calculation of relative humidity tendencies directly using RH from ERA5 may lead to small discrepancies if we compute RH tendencies as the sum of term II and term III of equation 4. Therefore, total RH tendencies or changes in this study is the sum of term II and term III of equation 4 rather than the RH variable itself. We account for these differences to the complexity of the ERA5 data assimilation schemes. In addition to using only two years of data, another bias using ERA5 is the overestimation of low cloud over south Cameroon compared to what is found in Dommo et al. (2018) (see their figure 2d). This is because ERA5 does not yet make any difference between stratiform and cumuliform clouds. Low 
clouds in south Cameroon may be mainly dominated by cumuliform clouds particularly cumulonimbus. Therefore, in situ measurements and radio soundings are needed to disentangle and quantify precisely the phenomena which drive observed LCCs formation, maintenance and dissipation over WCA. Nevertheless, the use of ERA5 allows us to analyse a panel of atmospheric processes relevant to LCCs in WCA. Results show some similar findings to southern west Africa (SWA): for instance, horizontal cold air advection after sunset and radiative cooling (Babic et al. 2019, Lehou et al. 2020) also drive the strong decrease in nighttime temperatures. Additionally, low level convergence (Kniffka et al 2019) is similar between SWA and WCA. Also demonstrated in this study is the role of upward mixing of moisture that accumulates in the low layers. This result has also been highlighted by Schrage and Fink (2012) in SWA. The added value of this work compared to what is found in SWA is the range of TKE. Indeed, if TKE is greater than $0.4 \mathrm{~m}^{2} . \mathrm{s}^{-2}$ in WCA, it acts to destroy the cloud layer.

The datasets used in this study are completely different from those used in similar studies over SWA where studies are mostly based on in situ observations and radiosondes. They were able to distinguish different phases in LCCs evolution along the diurnal cycle (Babic et al. 2019, Lehou et al. 2020, Alder et al. 2019), the atmospheric processes relevant to each phase, and to quantify them precisely. For instance, Alder et al. (2019) show that horizontal cold air advection contributes to $50 \%$ of cooling, whereas radiative flux divergence and sensible heat flux divergence contribute $20 \%$ and $22 \%$ (respectively) to cooling. Additionally, they highlighted the intensification of low-level jets during the jet phase. These are processes which we could not explore for WCA, due to the lack of observational datasets. Besides, Knippertz et al. (2011) also show the effects of aerosols on LCCs formation whereas Deetz et al. (2018) show that transitions from stratus to cumulus are highly sensitive to aerosols. On the other hand, the effects of gravity waves are not yet explored in WCA as it is pointed out by Babic et al. (2019b) for SWA. Therefore, many questions remain unanswered concerning the processes relevant to LCCs in WCA. For instance, in SWA, a clear characteristic between cloudy and non-cloudy nights is made, followed by the main factors leading to these differences. Nevertheless, this study has allowed us to lay the groundwork for an in-depth study of low clouds in WCA, a region that is still very poorly documented. This study also allowed us to considerably improve our knowledge of the LCCs for the region compared to the work of Dommo et al. (2018) and can help us to ameliorate our understanding of the climatic characteristics of the region and the improvement of the regional climate model 
645 simulations. 


\section{References}

Ackerman SA, Strabala KI, Menzel WP, Frey R, Moeller C, Gumley L (1998) Discriminating clear sky from clouds with MODIS. J Geophys Res: Atmospheres 103:32141-32157. doi: 10.1029/1998jd200032

Adler B, Babić K, Kalthoff N, Lohou F, Lothon M, Dione C, Pedruzo-Bagazgoitia X, Andersen H (2019) Nocturnal low-level clouds in the atmospheric boundary layer over southern West Africa: an observation-based analysis of conditions and processes. Atmos Chem Phys 19:663-681. doi: 10.5194/acp-19-663-2019

Babić K, Kalthoff N, Adler B, Quinting JF, Lohou F, Dione C, Lothon M (2019b) What controls the formation of nocturnal low-level stratus clouds over southern West Africa during the monsoon season? Atmos Chem Phys 19:13489-13506. doi: 10.5194/acp$19-13489-2019$

Babić K, Adler B, Kalthoff N, Andersen H, Dione C , Lohou F, Lothon M , PedruzoBagazgoitia X (2019a) The observed diurnal cycle of low-level stratus clouds over southern West Africa: a case study. Atmos Chem Phys 19:1281-1299. doi: 10.5194/acp-19-1281-2019

Cermak J (2012) Low clouds and fog along the South-Western African coast — Satellitebased retrieval and spatial patterns. Atmos Res 116:15-21. doi: 10.1016/j.atmosres.2011.02.012

Chen T, Rossow WB, Zhang Y (2000) Radiative Effects of Cloud-Type Variations. J Clim 13:264-286. doi: 10.1175/1520-0442(2000)013<0264:reoctv>2.0.co;2

Danso DK, Anquetin S, Diedhiou A, Lavaysse C, Kobea A, Touré NE (2019) Spatiotemporal variability of cloud cover types in West Africa with satellite-based and reanalysis data. Q J R Meteorol Soc 145:3715-3731. doi: 10.1002/qj.3651 
Deetz K, Vogel H, Knippertz P, et al (2018) Numerical simulations of aerosol radiative effects and their impact on clouds and atmospheric dynamics over southern West Africa. Atmos Chem Phys 18:9767-9788. doi: 10.5194/acp-18-9767-2018

Dommo A, Philippon N, Vondou DA, Sèze G, Eastman R (2018) The June-September Low Cloud Cover in Western Central Africa: Mean Spatial Distribution and Diurnal Evolution, and Associated Atmospheric Dynamics. J Clim 31:9585-9603. doi: 10.1175/jcli-d-17-0082.1

Fotso-Nguemo TC, Vondou DA, Tchawoua C, Haensler A (2016) Assessment of simulated rainfall and temperature from the regional climate model REMO and future changes over Central Africa. Clim Dyn 48:3685-3705. doi: 10.1007/s00382-016-3294-1

Fotso-Nguemo TC, Vondou DA, Pokam WM, Yepdo Djomou Z, Diallo I, Haensler A, Djiotang Tchotchou LA, Kamsu-Tamo PH, Gaye AT, Tchawoua C (2017) On the added value of the regional climate model REMO in the assessment of climate change signal over Central Africa. Clim Dyn 49:3813-3838. doi: 10.1007/s00382-017-3547-7

Garratt JR (1999) The atmospheric boundary layer. Cambridge University Press

Hahn CJ, Warren SG, London J (1995) The Effect of Moonlight on Observation of Cloud Cover at Night, and Application to Cloud Climatology. J Clim 8:1429-1446. doi: 10.1175/1520-0442(1995)008<1429:teomoo>2.0.co;2

Hahn C, Warren S (2007) A Gridded Climatology of Clouds over Land (1971-96) and Ocean (1954-97) from Surface Observations Worldwide. Carbon Dioxide Information Analysis Center (CDIAC) Datasets. doi: 10.3334/cdiac/cli.ndp026e

Hannak L, Knippertz P, Fink AH, et al (2017) Why Do Global Climate Models Struggle to Represent Low-Level Clouds in the West African Summer Monsoon? J Clim 30:1665-1687. doi: 10.1175/jcli-d-16-0451.1 
Hartmann DL, Ockert-Bell ME, Michelsen ML (1992) The Effect of Cloud Type on Earth's Energy Balance: Global Analysis. J Clim 5:1281-1304. doi: 10.1175/15200442(1992)005<1281:teocto >2.0.co;2

Hersbach H, Rosnay Pde, Bell B (2018) Operational global reanalysis progress, future directions and synergies with NWP. European Centre for Medium Range Weather Forecasts

Klein SA, Hartmann DL (1993) The Seasonal Cycle of Low Stratiform Clouds. J Clim 6:1587-1606. doi: 10.1175/1520-0442(1993)006<1587:tscols >2.0.co;2

Kniffka A, Knippertz P, Fink AH (2019) The role of low-level clouds in the West African monsoon system. Atmos Chem Phys 19:1623-1647. doi: 10.5194/acp-19-1623-2019

Knippertz P, Fink AH, Schuster R, Trentmann J, Schrage JM, Yorke C (2011) Ultra-low clouds over the southern West African monsoon region. Geophys Res Lett. doi: $10.1029 / 2011 \mathrm{~g} 1049278$

Kuete G, Mba WP, Washington R (2019) African Easterly Jet South: control, maintenance mechanisms and link with Southern subtropical waves. Clim Dyn 54:1539-1552. doi: 10.1007/s00382-019-05072-w

Lei Y, Letu H, Shang H, Shi J (2020) Cloud cover over the Tibetan Plateau and eastern China: a comparison of ERA5 and ERA-Interim with satellite observations. Clim Dyn 54:2941-2957. doi: 10.1007/s00382-020-05149-х

Lohou F, Kalthoff N, Adler B, Babi K, Dione C, Lothon M, Pedruzo-Bagazgoitia X, Zouzoua M (2020) Conceptual model of diurnal cycle of low-level stratiform clouds over southern West Africa. Atmos Chem Phys 20:2263-2275. doi: 10.5194/acp-20$2263-2020$ 
Maddux BC, Ackerman SA, Platnick S (2010) Viewing Geometry Dependencies in MODIS Cloud Products. J Atmos Oceanic Technol 27:1519-1528. doi: $10.1175 / 2010$ jtecha1432.1

Mba WP, Longandjo G-NT, Moufouma-Okia W, Bell JP, James R, Vondou DA, Haensler A, Fotso Nguemo TC, Guenang GM, Djiotang Tchotchou AL, Kamsu-Tamo PH, Takong RR, Grigory N, Lennard CJ, Dosio A (2018) Consequences of $1.5^{\circ} \mathrm{C}$ and $2{ }^{\circ} \mathrm{C}$ global warming levels for temperature and precipitation changes over Central Africa. Environ Res Lett 13:055011. doi: 10.1088/1748-9326/aab048

Oreopoulos L (2005) The impact of subsampling on MODIS level-3 statistics of cloud optical thickness and effective radius. IEEE Transactions on Geoscience and Remote Sensing 43:366-373. doi: 10.1109/tgrs.2004.841247

Paluch IR, Lenschow DH (1991) Stratiform Cloud Formation in the Marine Boundary Layer. J Atmos Sci 48:2141-2158. doi: 10.1175/15200469(1991)048<2141:scfitm>2.0.co;2

Philippon N, Cornu G, Monteil L, Gond V, Moron V, Pergaud J, Sèze G, Bigot S, Camberlin P, Doumenge C, Fayolle A, Ngomanda A (2019) The light-deficient climates of western Central African evergreen forests. Environ Res Lett 14:034007. doi: $10.1088 / 1748-9326 /$ aaf5d8

Pilié RJ, Mack EJ, Rogers CW, Katz U, Kocmond WC (1979) The Formation of Marine Fog and the Development of Fog-Stratus Systems along the California Coast. J Appl Meteorol 18:1275-1286. doi: 10.1175/1520-0450(1979)018<1275:tfomfa>2.0.co;2 Pokam WM, Bain CL, Chadwick RS, Graham R, Sonwa DJ, Mkankam Kamga F (2014) Identification of Processes Driving Low-Level Westerlies in West Equatorial Africa. J Clim 27:4245-4262. doi: 10.1175/jcli-d-13-00490.1 
Schrage JM, Augustyn S, Fink AH (2007) Nocturnal stratiform cloudiness during the West Africa monsoon. Meteorol Atmos Phys 96: 73-86. doi: 10.1007/s00703-006-0194-7 Schrage JM, Fink AH (2012) Nocturnal Continental Low-Level Stratus over Tropical West Africa: Observations and Possible Mechanisms Controlling Its Onset. Mon Weather Rev 140:1794-1809. doi: 10.1175/mwr-d-11-00172.1

Schuster R, Fink AH, Knippertz P (2013) Formation and Maintenance of Nocturnal LowLevel Stratus over the Southern West African Monsoon Region during AMMA 2006. J Atmos Sci 70:2337-2355. doi: 10.1175/jas-d-12-0241.1

Solomon S (2007) Climate change 2007: the physical science basis. Published for the IPCC by Cambridge University Press

Sonkoué D, Monkam D, Fotso-Nguemo TC, Yepdo ZD, Vondou DA (2018) Evaluation and projected changes in daily rainfall characteristics over Central Africa based on a multimodel ensemble mean of CMIP5 simulations. Theor Appl Climatol 137:2167-2186. doi: $10.1007 / \mathrm{s} 00704-018-2729-5$

Stephens GL (1978) Radiation Profiles in Extended Water Clouds. I: Theory. J Atmos Sc 35:2111-2122. doi: 10.1175/1520-0469(1978)035<2111:rpiewc > 2.0.co;2

Stephens GL, Greenwald TJ (1991) The Earth's radiation budget and its relation to atmospheric hydrology: 2. Observations of cloud effects. J Geophys Res 96:15325. doi: 10.1029/91jd00972

Stevens B (2002) Entrainment in stratocumulus-topped mixed layers. Q J R Meteorol Soc 128:2663-2690. doi: 10.1256/qj.01.202

Sun J, Angal A, Xiong X, et al (2012) MODIS reflective solar bands calibration improvements in Collection 6. Earth Observing Missions and Sensors: Development, Implementation, and Characterization II. doi: 10.1117/12.979733 
Tamoffo AT, Vondou DA, Pokam WM, Haenler A, Yepdo ZD, Fotso-Nguemo TC, Djiotang Tchotchou LA, Nouayou R (2019a) Daily characteristics of Central African rainfall in the REMO model. Theor Appl Climatol 137:2351-2368. doi: 10.1007/s00704-018$2745-5$

Tamoffo AT, Nikulin G, Vondou DA, Dosio A, Nouayou R, Wu M, Igri PM (2021) Processbased assessment of the impact of reduced turbulent mixing on Congo Basin precipitation in the RCA4 Regional Climate Model. Clim Dyn. doi: 10.1007/s00382020-05571-1

Vondou DA, Haensler A (2017) Evaluation of simulations with the regional climate model REMO over Central Africa and the effect of increased spatial resolution. Int J Climatol 37:741-760. doi: 10.1002/joc.5035

Wood R (2012) Stratocumulus Clouds. Mon Weather Rev 140:2373-2423. doi: 10.1175/mwr-d-11-00121.1

Zouzoua M, Lohou F, Assamoi P, Lothon M, Yoboue V, Dione C, Kalthoff N, Alder B, Babic K, Pedruzo-Bagazgoitia X, Derrien S (2021) Breakup of nocturnal low-level stratiform clouds during the southern West African monsoon season. Atmos Chem Phys 21:2027-2051. doi: 10.5194/acp-21-2027-2021 
782

783

784

785

786

787

788

789

790

791

792

793

794

795

796

797

798

799

800

801

802

803

804

805

\section{List of figures}

1 Topography of the study area. Red triangles indicate the 18 EECRA stations used in this study

2 Diurnal cycle of low cloud fraction for each year from 1979 to 2019 (grey lines) and in 2014 (red line) and 2015 (black line) spatially averaged over $6^{\circ} \mathrm{S}-5^{\circ} \mathrm{N} / 8^{\circ} \mathrm{E}-15^{\circ} \mathrm{E}$. Landonly pixels are considered

3 Mean JJAS spatial distribution of low clouds cover in WCA from a) MODIS satellite observation, b) ERA5 reanalysis, c) land station observation (EECRA) and d) diurnal cycle of LCC. Triangles in panel c indicate EECRA stations. For diurnal cycle (d), only ERA5 pixels documenting the 18 EECRA stations are used, and the error bars indicate the standard deviation of diurnal cycle across the grid points corresponding to EECRA stations. For EECRA observations, only stations recording at least $25 \%$ of the data for the JJAS seasons over the 39-year ECCRA observation have been used. The diurnal cycle is computed within the green box considering only ERA5 pixels documenting EECRA stations (Fig 1). The red dashed curve indicates the difference between EECRA and ERA5

4 Mean spatial evolution of low clouds cover during the diurnal cycle for ERA5 (panel a), and EECRA (panel b). Black dots on panel a) are pixels with at least $80 \%$ of low cloud fraction at 07LT. Triangles (panel b) indicates EECRA stations. For EECRA, only stations (18) recording at least $25 \%$ of the data for the JJAS seasons over the 39 -year EECRA observation period have been used. Time series (panel c) of total column water vapor (TWV, blue line) and total column cloud liquid water content (LWP, red line) within the green box. Only ERA5 pixels the closest to EECRA stations (Fig 1) are considered for times series computation. 
5 Time-height evolution of ERA5 relative humidity (shadings in \%) and horizontal wind speed in $\mathrm{m} / \mathrm{s}$ (contour) averaged over $6^{\circ} \mathrm{S}-5^{\circ} \mathrm{N} / 8^{\circ} \mathrm{E}-15^{\circ} \mathrm{E}$. Only land pixels with at least $80 \%$ of low clouds cover at $07 \mathrm{LT}$ are considered for spatial average. The wind speed values are indicated in red. The arrows show the horizontal wind vectors displayed as usual on a lon-lat map. Computations are made from ground level (pressure $<1000$ $\mathrm{hPa})$

6 ERA5 Three-hourly vertical profiles from ground level of (a) cloud fraction (\%), (b) specific humidity, (c) moisture advection, (d) divergence of moisture advection, (e) turbulent kinetic energy, and (f) static stability. Time series of g) specific humidity, h) relative humidity (black line) and temperature (red line) and, i) horizontal wind speed at $925 \mathrm{hPa}$ i.e about 790m from ground level. Spatial averages are made considering landonly pixels which record at least $80 \%$ of low cloud at $07 \mathrm{LT}$

7 Scatter plots between low level cloud fraction anomaly and moisture advection at $925 \mathrm{hPa}$ during the diurnal cycle. The scatter plot is obtained by averaging land only pixels which record at least $80 \%$ in low cloud fraction at $07 \mathrm{LT}$ within the box $6^{\circ} \mathrm{S}-5^{\circ} \mathrm{N} / 8^{\circ} \mathrm{E}-$ $15^{\circ} \mathrm{E}$ for the period $2014-2015$. For each time slot $(01,04,07,10,13,16,19 \& 22 \mathrm{LT})$, the mean advection (Adv) and the mean low cloud cover anomaly (M) and correlation coefficient (CC) are computed. The regression line between the two variables is represented in black, and the reference line $(\mathrm{y}=0)$ is in green

8 Same as fig 7 but between low cloud fraction anomaly and moisture divergence at $950 \mathrm{hPa}$. For each time slot, Div denotes the mean divergence. Negative (positive) values of divergence expressed moisture inflow (outflow)

9 ERA5 Three-hourly vertical profiles of wind (blue line) and specific humidity (green line) mean contribution to total advection change (red) from the ground level (pressure $<1000$ ) averaged over $6^{\circ} \mathrm{S}-5^{\circ} \mathrm{N} / 8^{\circ} \mathrm{E}-15^{\circ} \mathrm{E}$ for the period $2014-2015$. Only land pixels 
with at least $80 \%$ of cloud fraction at $07 \mathrm{LT}$ are considered for spatial average

10 ERA5 Three-hourly vertical profiles of zonal (magenta) and meridional (cyan) wind contribution to total advection change (black) from the ground level (pressure <1000) within $6^{\circ} \mathrm{S}-5^{\circ} \mathrm{N} / 8^{\circ} \mathrm{E}-15^{\circ} \mathrm{E}$ for the period $2014-2015$. Only land pixels with at least $80 \%$ of low cloud fraction at 07LT are considered for spatial average

11 a-e) ERA5 vertical profiles of specific humidity (q) and temperature (T) contribution to relative humidity $(\mathrm{RH})$ changes from early evening to early morning $(19,22,01,04$, and 07LT). f) average for the five time slots. g) cooling rate from early evening to early morning $(19,22,01,04$, and 07LT). The magenta line is the average of the 5 time-slots. Calculations are made from ground level (pressure $<1000 \mathrm{hPa}$ ) considering land only pixels with at least $80 \%$ of low cloud fraction at $07 \mathrm{LT}$ within $6^{\circ} \mathrm{S}-5^{\circ} \mathrm{N} / 8^{\circ} \mathrm{E}-15^{\circ} \mathrm{E}$ for the period 2014-2015

12 Diurnal cycle of a) radiative balance (Net radiation: $\mathrm{R}^{*}$, surface net shortwave radiation: $R_{S}$, Net long wave radiation: $\left.R_{L}, \mathrm{~b}\right)$ energy balance (sensible heat, latent heat) and c) evaporation within $6^{\circ} \mathrm{S}-5^{\circ} \mathrm{N} / 8^{\circ} \mathrm{E}-15^{\circ} \mathrm{E}$ for the period 2014-2015. Only land pixels recording at least $80 \%$ in low cloud fraction are considered for spatial average. Error bars indicate the interquartile ranges

13 Conceptual schematic model illustrating the cloud formation and dissipation processes over WCA along the diurnal cycle. The dark blue lines represent the vertical profiles of the horizontal wind with an indication of its maximum value at evening (19, 22 LT), late night $(01,04,07 \mathrm{LT})$ and daytime $(10,13,16 \mathrm{LT})$. The dark curled arrows symbolize mixing due to nocturnal turbulence. Maximum values for the contribution of each process are given. Each value is obtained from ERA5 within $6^{\circ} \mathrm{S}-5^{\circ} \mathrm{N} / 8^{\circ} \mathrm{E}-15^{\circ} \mathrm{E}$ for the period 2014-2015 


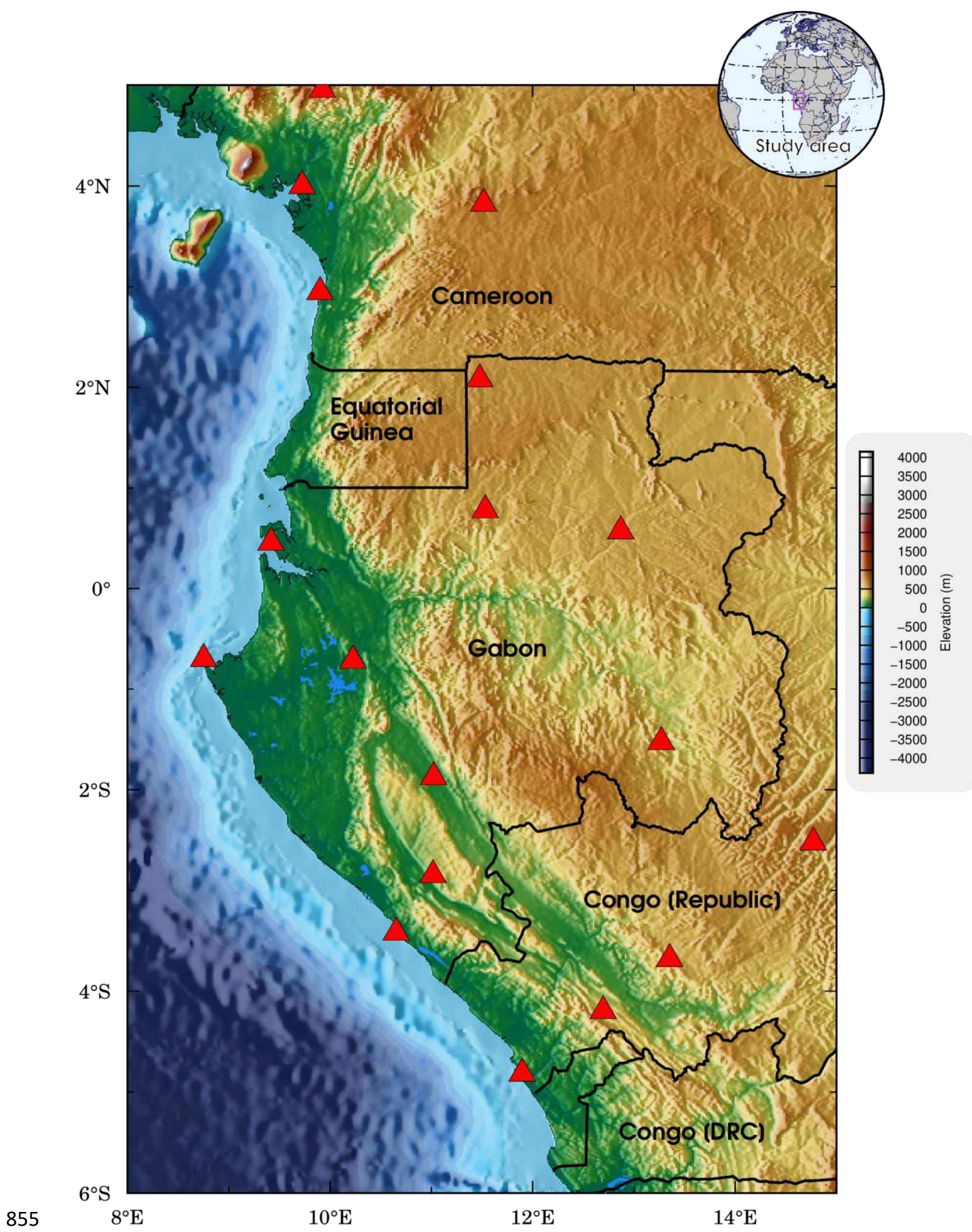

856 Fig. 1 Topography of the study area. Red triangles indicate the 18 EECRA stations used in this study 


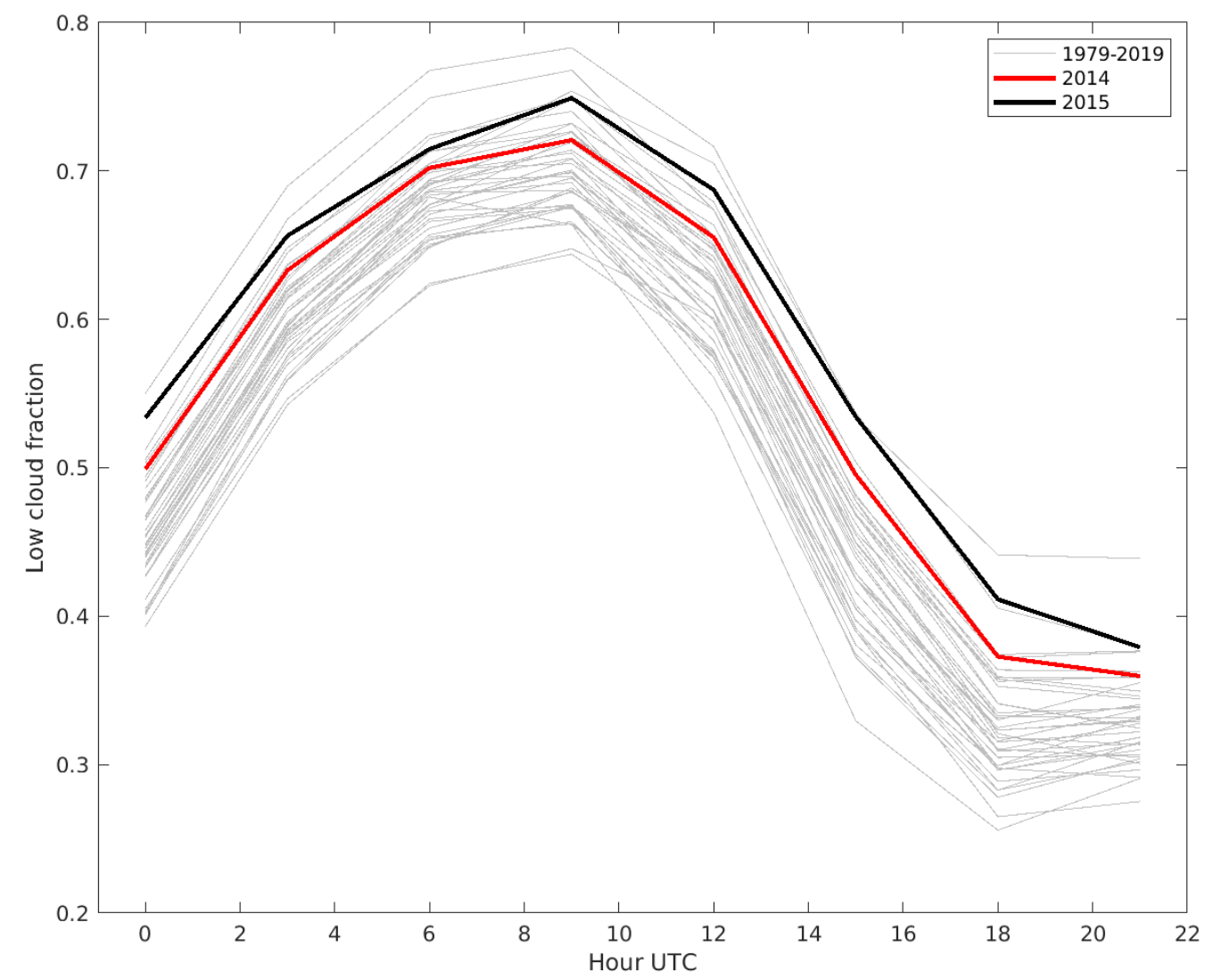

858

859 Fig. 2 Diurnal cycle of low cloud fraction for each year from 1979 to 2019 (grey lines) and in 860 2014 (red line) and 2015 (black line) spatially averaged over $6^{\circ} \mathrm{S}-5^{\circ} \mathrm{N} / 8^{\circ} \mathrm{E}-15^{\circ} \mathrm{E}$. Land-

861 only pixels are considered 
a) Terra+Aqua Modis
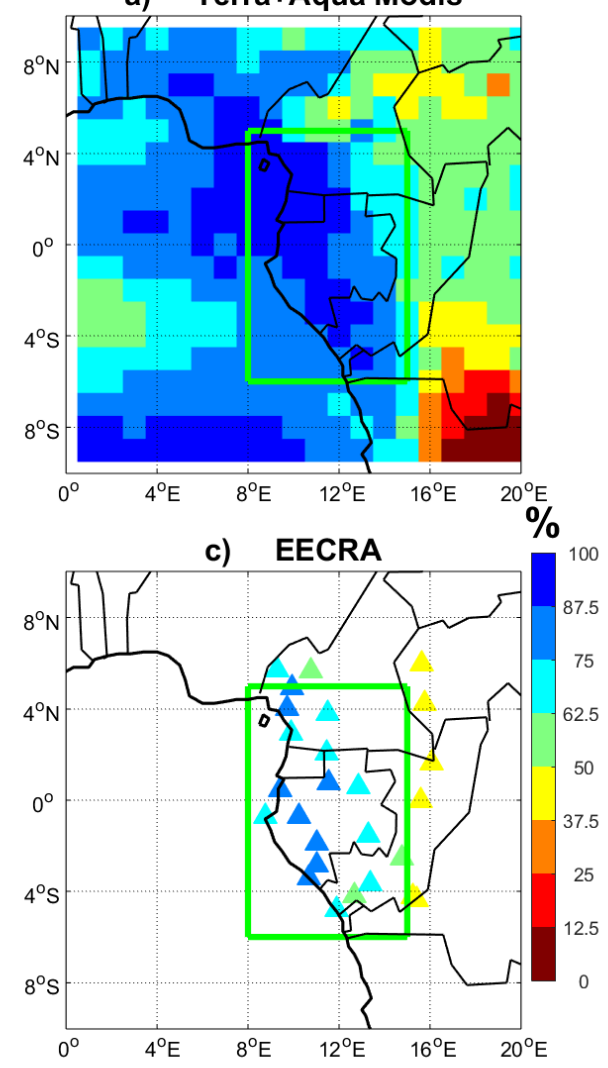

b) ERA5
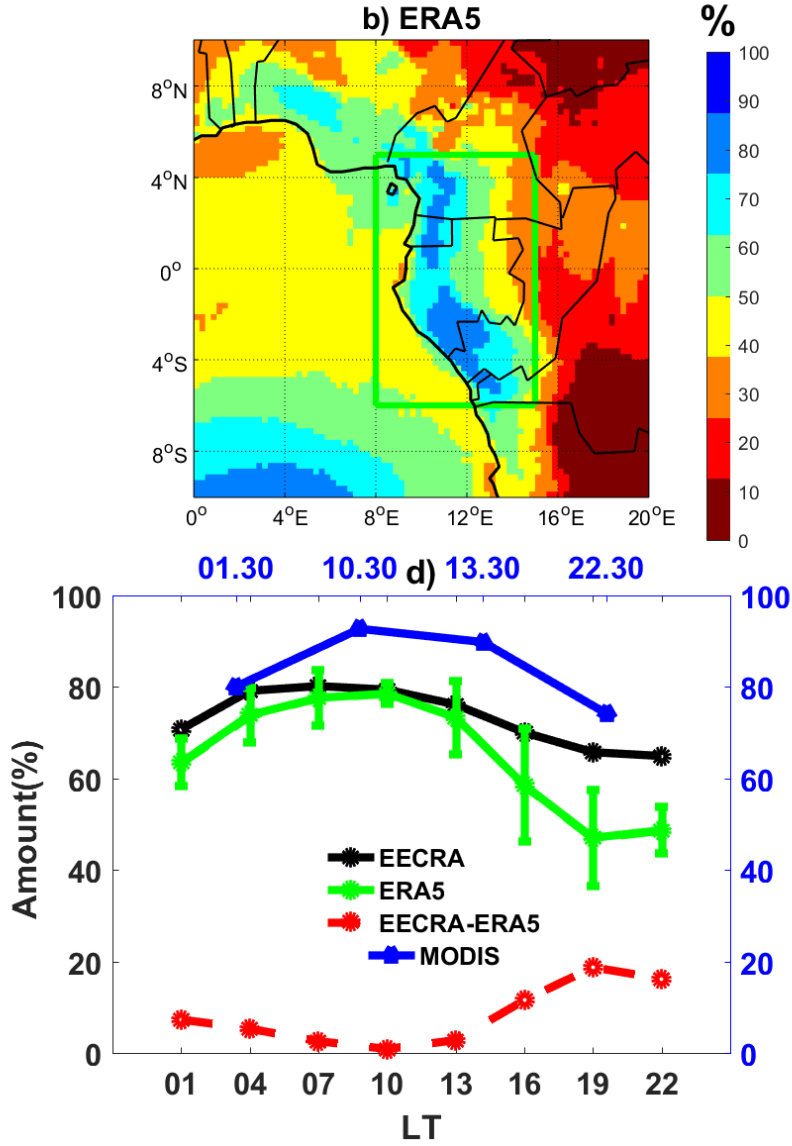

862

863

Fig. 3 Mean JJAS spatial distribution of low clouds cover in WCA from a) MODIS satellite observation, b) ERA5 reanalysis, c) land station observation (EECRA) and d) diurnal cycle of LCC. Triangles in panel c indicate EECRA stations. For diurnal cycle (d), only ERA5 pixels documenting the 18 EECRA stations are used, and the error bars indicate the standard deviation of diurnal cycle across the grid points corresponding to EECRA stations. For EECRA observations, only stations recording at least $25 \%$ of the data for the JJAS seasons over the 39-year ECCRA observation have been used. The diurnal cycle is computed within the green box considering only ERA5 pixels documenting EECRA stations (Fig 1). The red dashed curve indicates the difference between EECRA and ERA5 

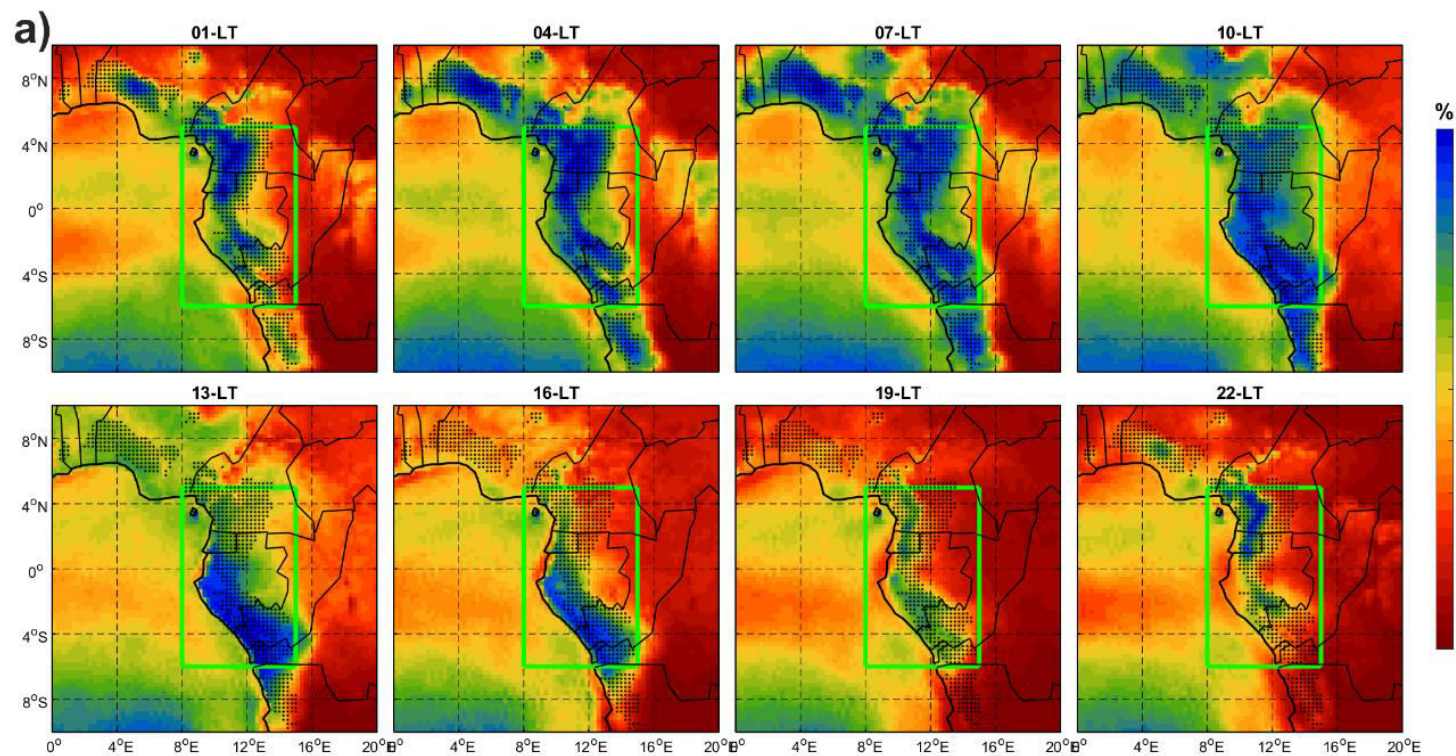

b)
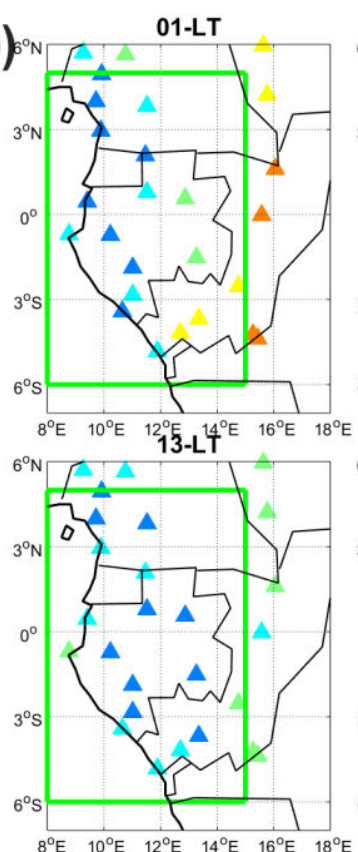
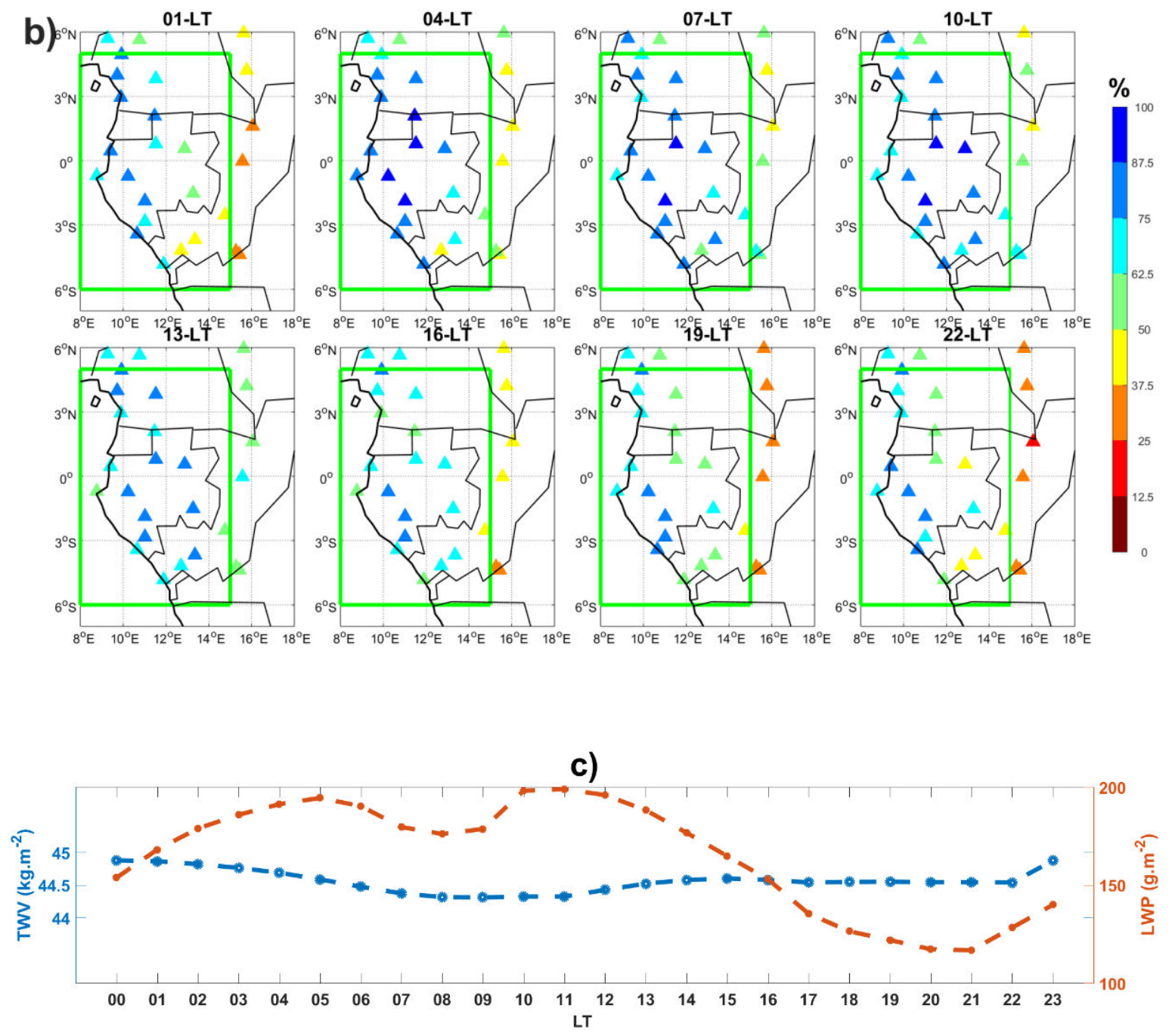

876 Fig. 4 Mean spatial evolution of low clouds cover during the diurnal cycle for ERA5 (panel 
a), and EECRA (panel b). Black dots on panel a) are pixels with at least $80 \%$ of low cloud fraction at 07LT. Triangles (panel b) indicates EECRA stations. For EECRA, only stations (18) recording at least $25 \%$ of the data for the JJAS seasons over the 39 year EECRA observation period have been used. Time series (panel c) of total column water vapor (TWV, blue line) and total column cloud liquid water content (LWP, red line) within the green box. Only ERA5 pixels the closest to EECRA stations (Fig 1) are considered for times series computation. 


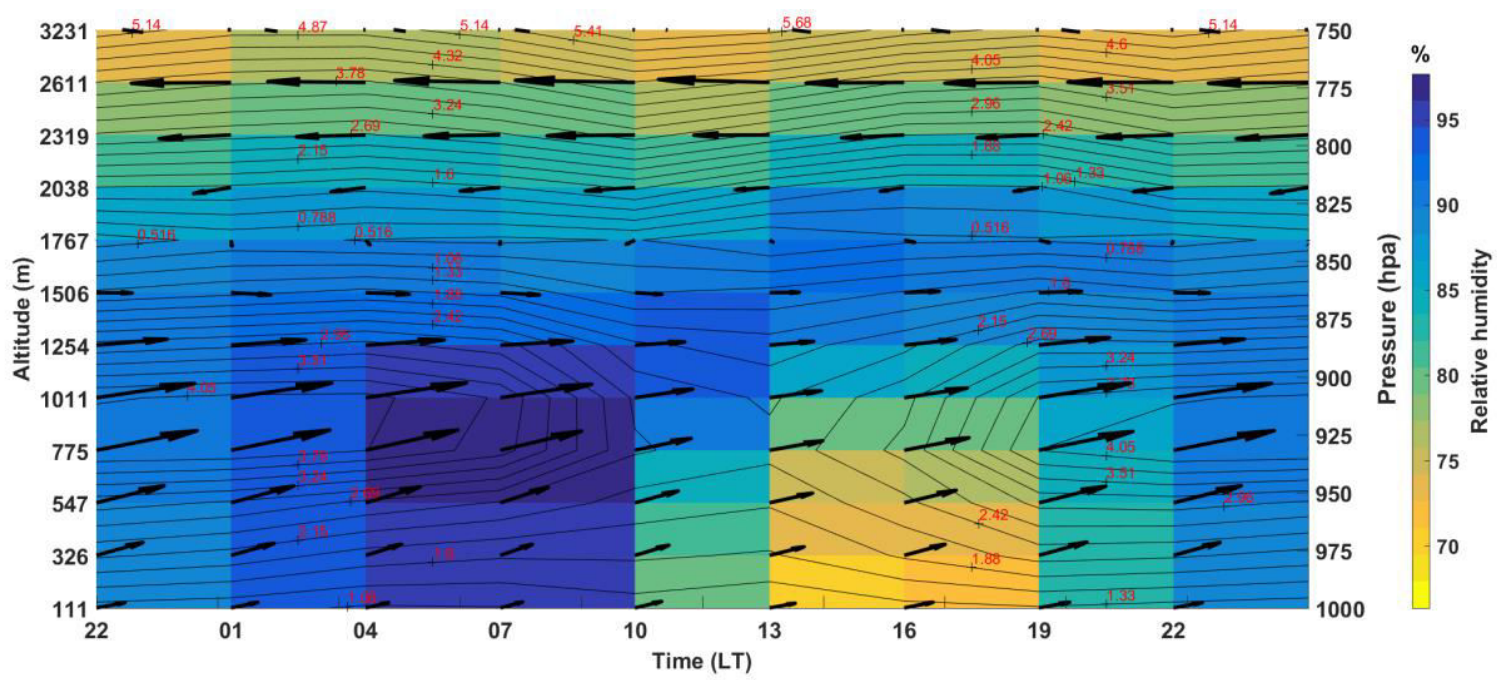

884

885 Fig. 5 Time-height evolution of ERA5 relative humidity (shadings in \%) and horizontal wind speed in $\mathrm{m} / \mathrm{s}$ (contour) averaged over $6^{\circ} \mathrm{S}-5^{\circ} \mathrm{N} / 8^{\circ} \mathrm{E}-15^{\circ} \mathrm{E}$. Only land pixels with at least $80 \%$ of low clouds cover at $07 \mathrm{LT}$ are considered for spatial average. The wind speed values are indicated in red. The arrows show the horizontal wind vectors displayed as usual on a lon-lat map. Computations are made from ground level (pressure $<1000$ $\mathrm{hPa})$ 

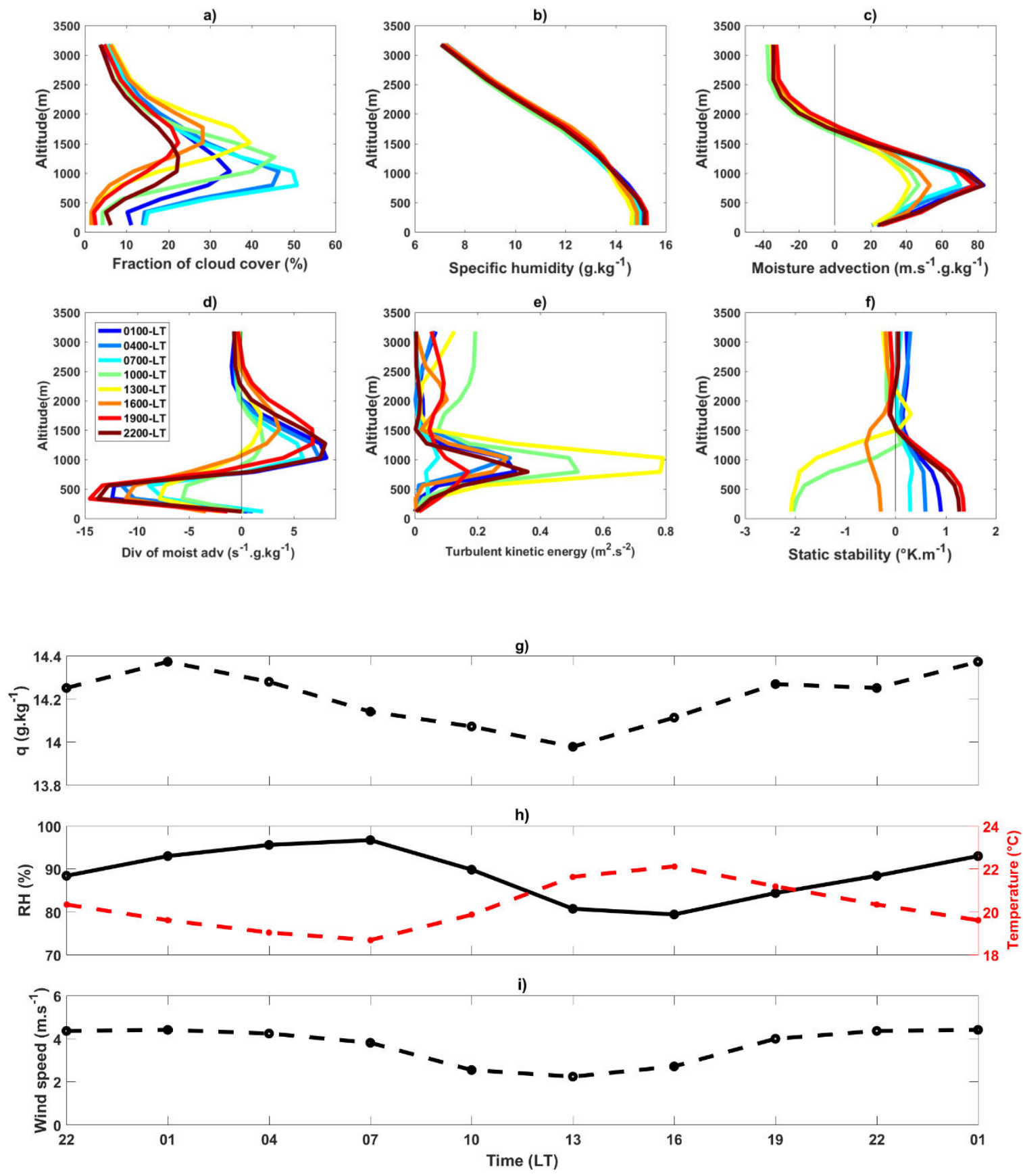

Fig. 6 ERA5 Three-hourly vertical profiles from ground level of (a) cloud fraction (\%), (b) specific humidity, (c) moisture advection, (d) divergence of moisture advection, (e) turbulent kinetic energy, and (f) static stability. Time series of g) specific humidity, h) relative humidity (black line) and temperature (red line) and, i) horizontal wind speed at $925 \mathrm{hPa}$ i.e about 790m from ground level. Spatial averages are made considering landonly pixels which record at least $80 \%$ of low cloud at $07 \mathrm{LT}$ 


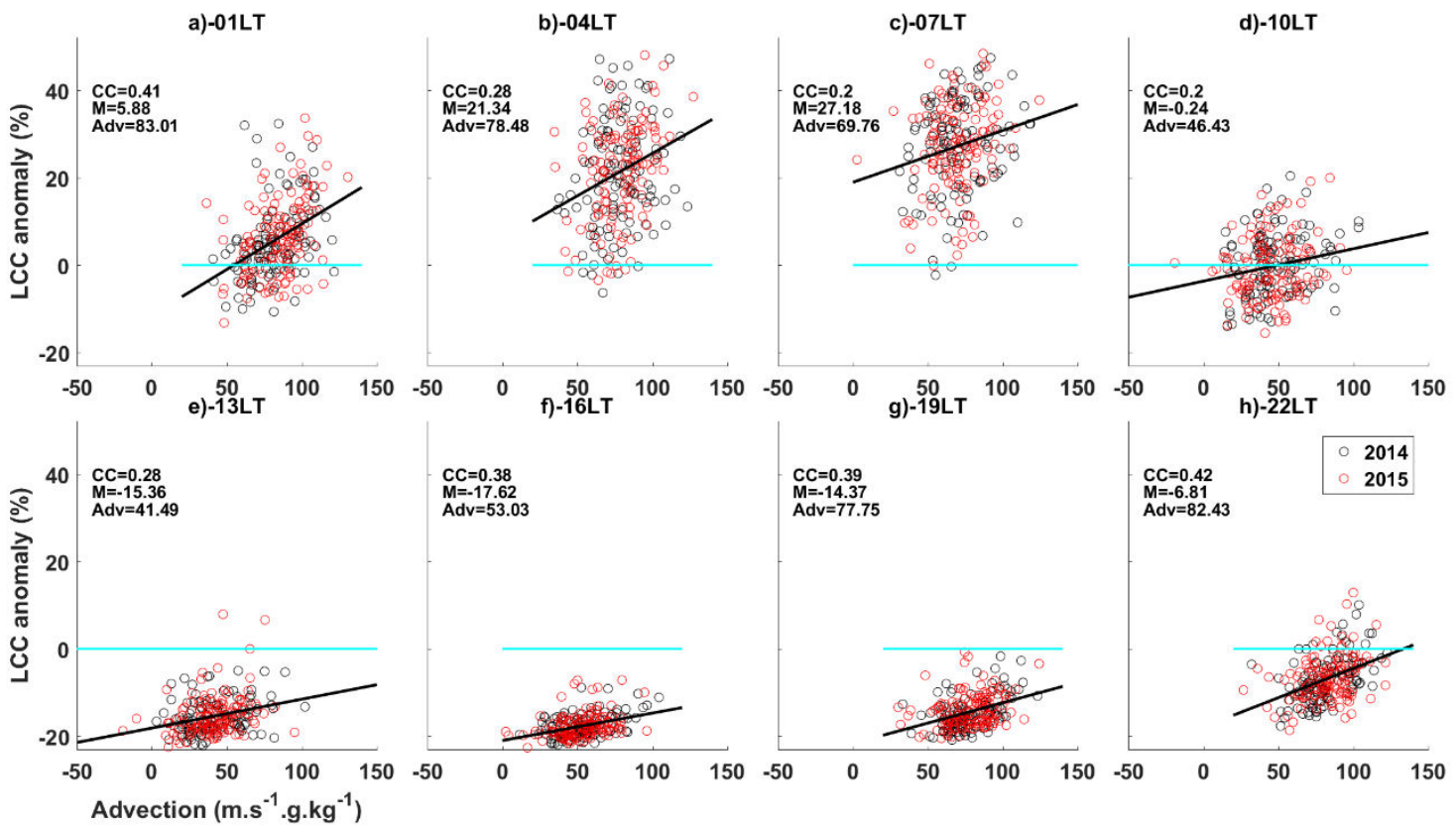

900 Fig. 7 Scatter plot between low level cloud fraction anomaly and moisture advection at 925 $\mathrm{hPa}$ during the diurnal cycle. The scatter plot is obtained by averaging land only pixels which record at least $80 \%$ in low cloud fraction at $07 \mathrm{LT}$ within the box $6^{\circ} \mathrm{S}-5^{\circ} \mathrm{N} / 8^{\circ} \mathrm{E}-$ $15^{\circ} \mathrm{E}$ for the period $2014-2015$. For each time slot $(01,04,07,10,13,16,19 \& 22 \mathrm{LT})$, the mean advection (Adv) and the mean low cloud cover anomaly (M) and correlation coefficient (CC) are computed. The regression line between the two variables is represented in black, and the reference line $(\mathrm{y}=0)$ is in green 

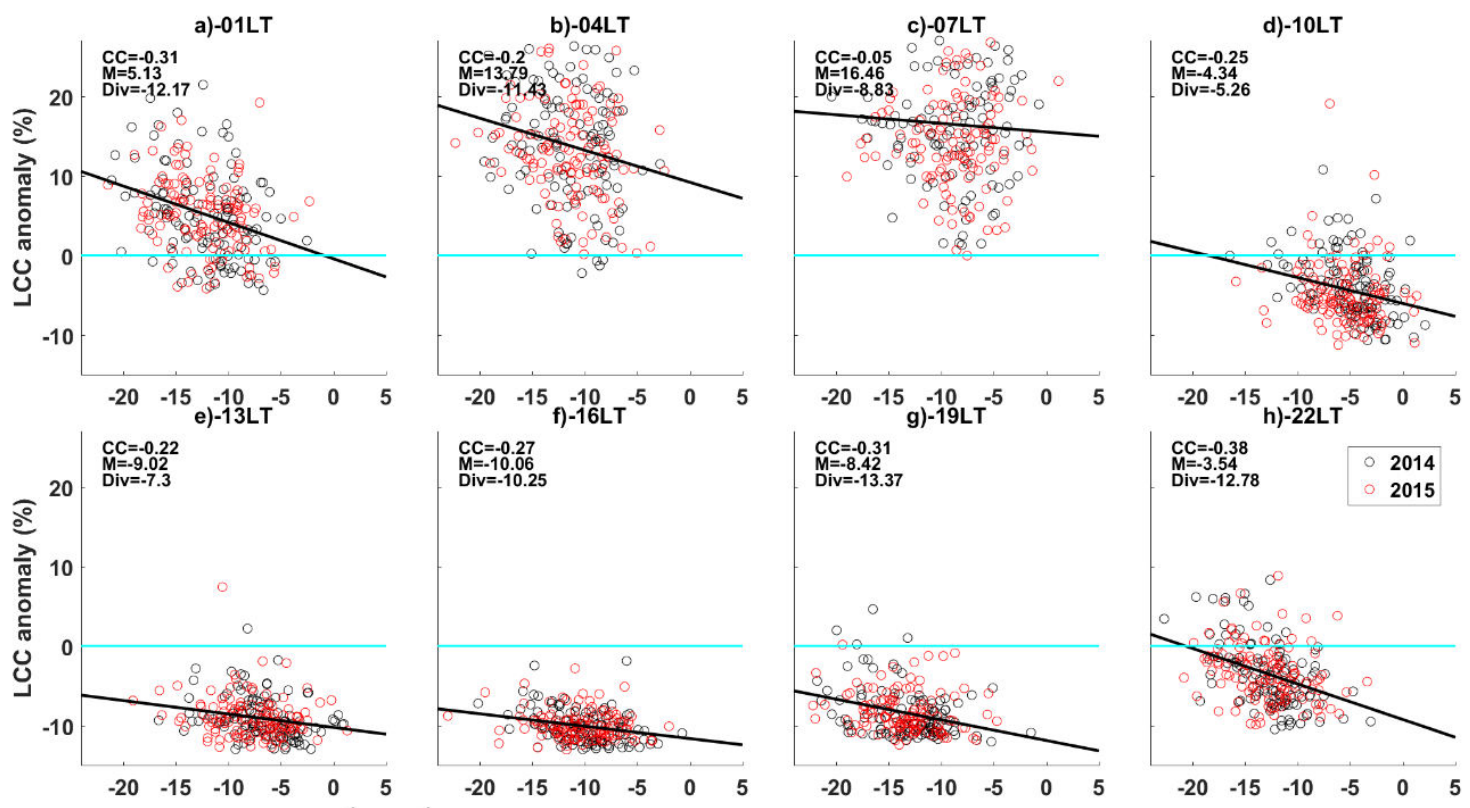
Moisture flux divergence $\left(\mathrm{s}^{-1} \cdot \mathrm{g} \cdot \mathrm{kg}^{-1}\right)$

908

909 Fig. 8 Same as fig 7 but between low cloud fraction anomaly and moisture divergence at 950 $\mathrm{hPa}$. For each time slot, Div denotes the mean divergence. Negative (positive) values of divergence expressed moisture inflow (outflow) 

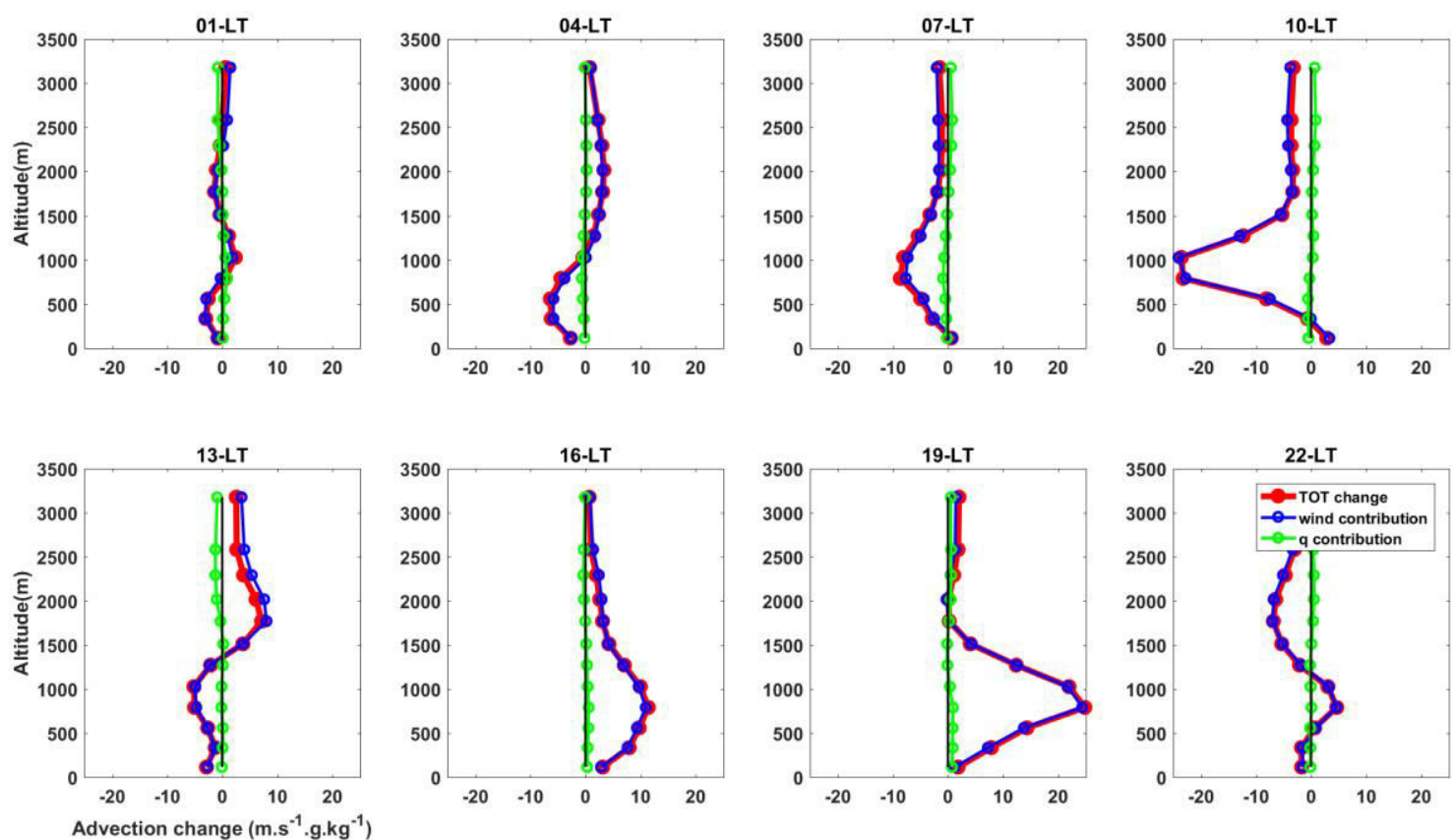

913 Fig. 9 ERA5 Three-hourly vertical profiles of wind (blue line) and specific humidity (green line) mean contribution to total advection change (red) from the ground level (pressure $<1000$ ) averaged over $6^{\circ} \mathrm{S}-5^{\circ} \mathrm{N} / 8^{\circ} \mathrm{E}-15^{\circ} \mathrm{E}$ for the period $2014-2015$. Only land pixels with at least $80 \%$ of cloud fraction at $07 \mathrm{LT}$ are considered for spatial average 

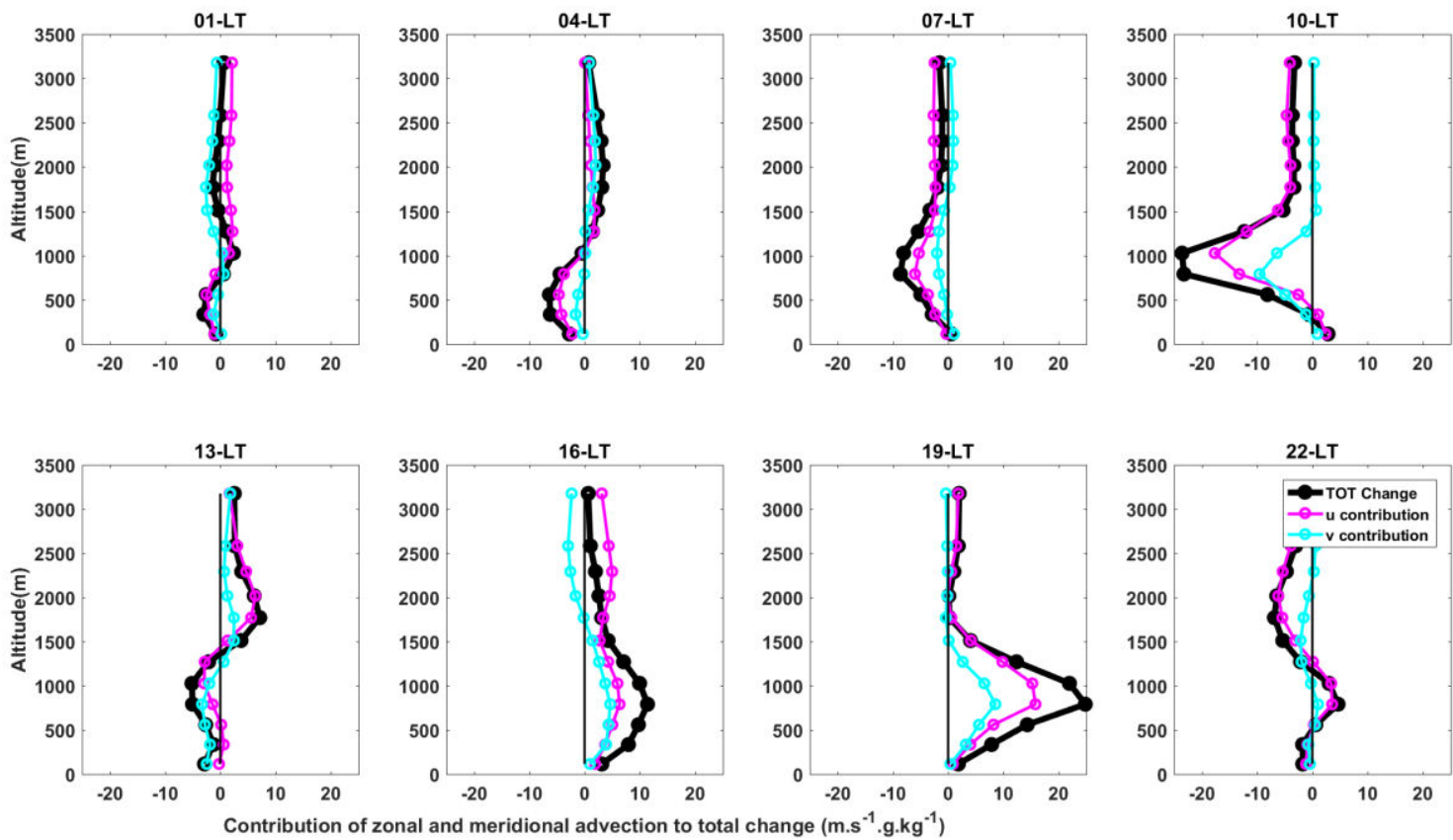

918

919 Fig. 10 ERA5 Three-hourly vertical profiles of zonal (magenta) and meridional (cyan) wind contribution to total advection change (black) from the ground level (pressure <1000) within $6^{\circ} \mathrm{S}-5^{\circ} \mathrm{N} / 8^{\circ} \mathrm{E}-15^{\circ} \mathrm{E}$ for the period $2014-2015$. Only land pixels with at least $80 \%$ of low cloud fraction at 07LT are considered for spatial average 

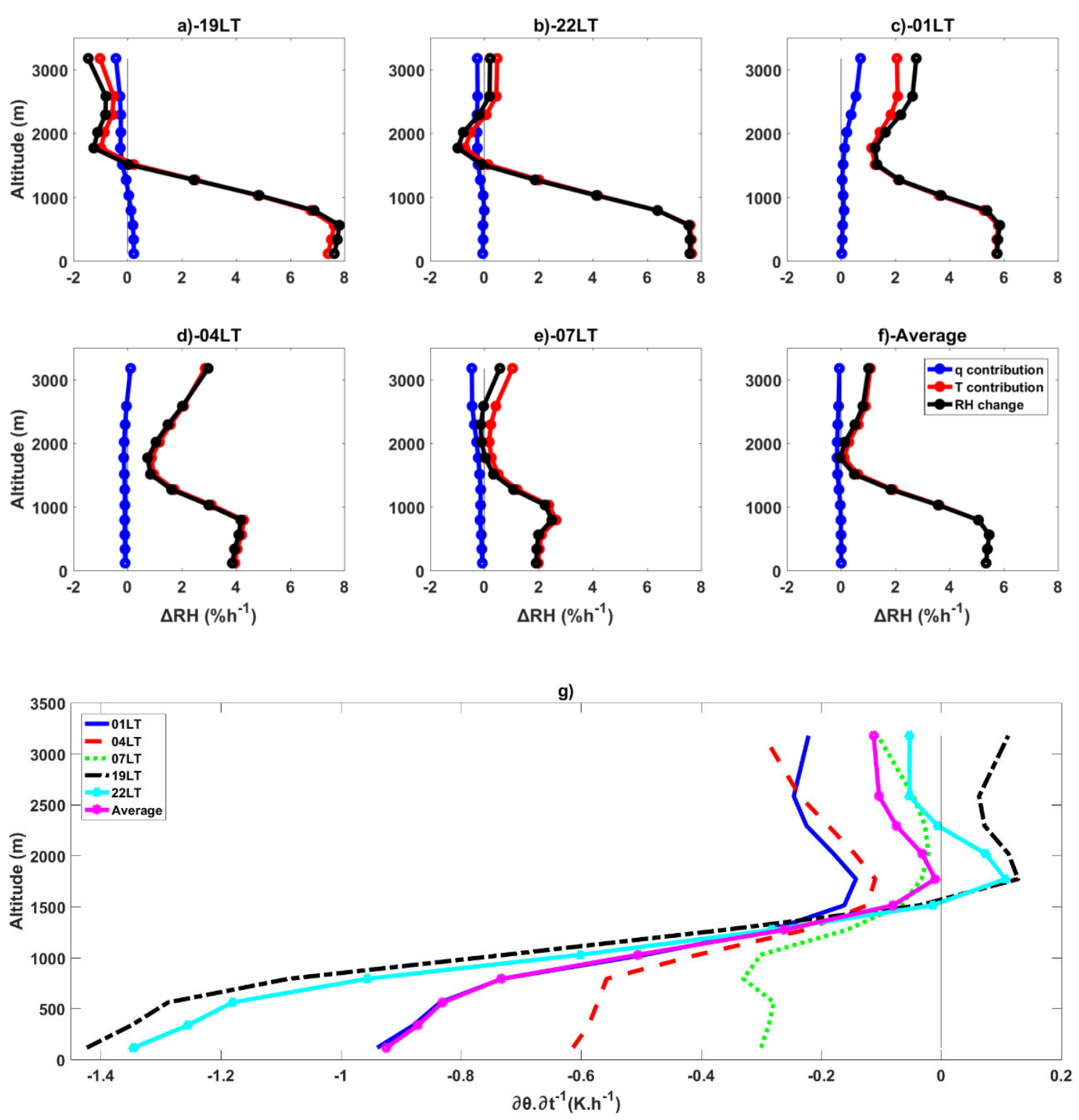

924

Fig. 11 a-e) ERA5 vertical profiles of specific humidity (q) and temperature (T) contribution to relative humidity $(\mathrm{RH})$ changes from early evening to early morning $(19,22,01,04$, and 07LT). f) average for the five time slots. g) cooling rate from early evening to early morning $(19,22,01,04$, and 07LT). The magenta line is the average of the 5 time-slots. Calculations are made from ground level (pressure $<1000 \mathrm{hPa}$ ) considering land only pixels with at least $80 \%$ of low cloud fraction at $07 \mathrm{LT}$ within $6^{\circ} \mathrm{S}-5^{\circ} \mathrm{N} / 8^{\circ} \mathrm{E}-15^{\circ} \mathrm{E}$ for the period 2014-2015 
a)

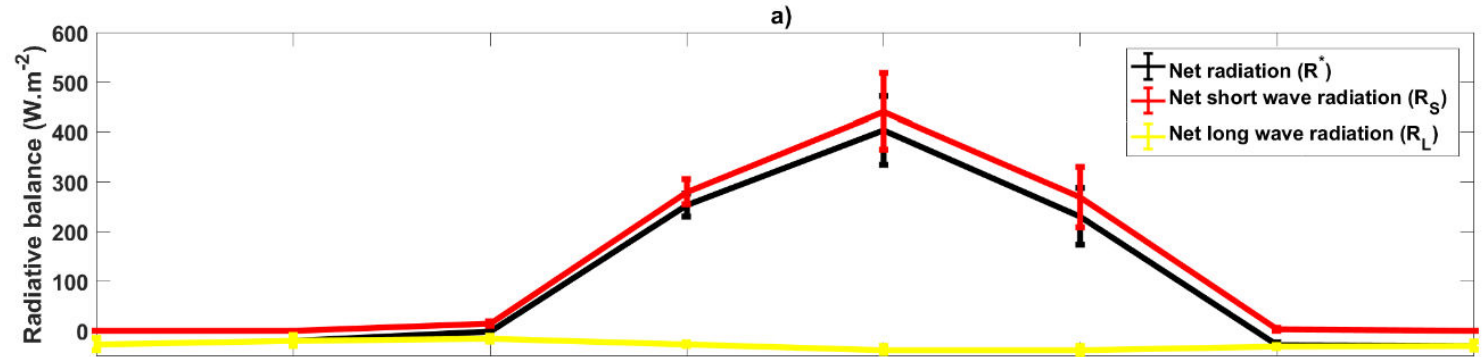

b)

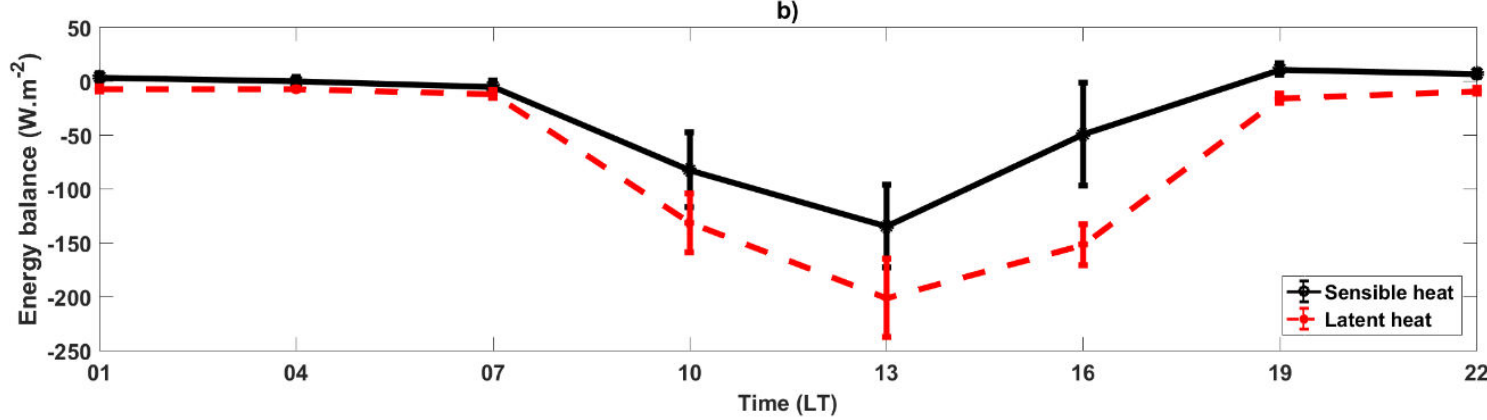

932

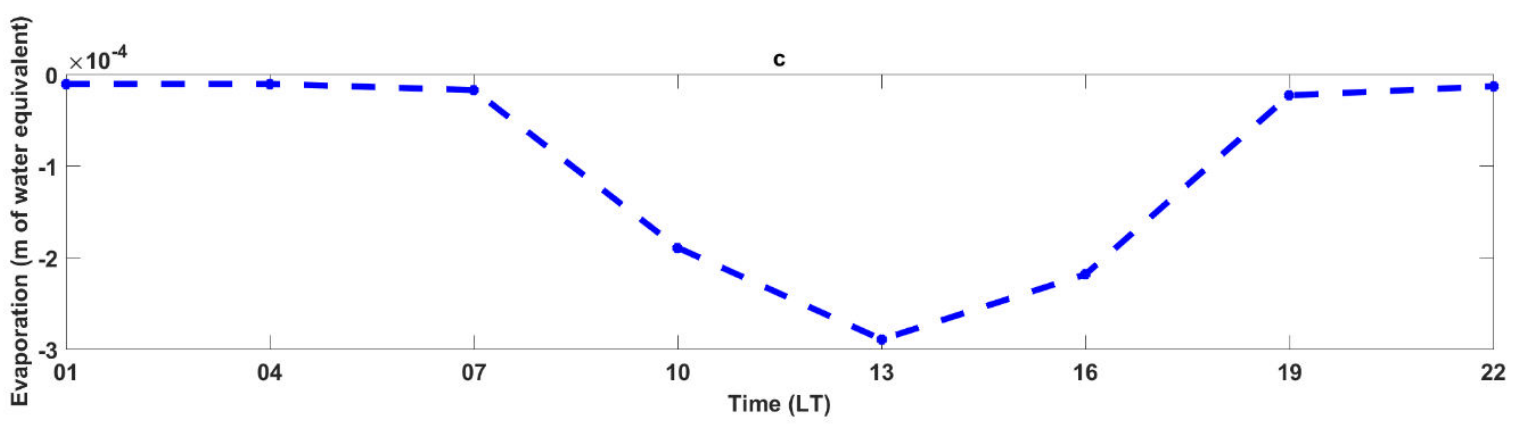

933

Fig. 12 Diurnal cycle of a) radiative balance (Net radiation: $R^{*}$, surface net shortwave radiation: , Net long wave radiation: , b) energy balance (sensible heat, latent heat) and c) evaporation within $6^{\circ} \mathrm{S}-5^{\circ} \mathrm{N} / 8^{\circ} \mathrm{E}-15^{\circ} \mathrm{E}$ for the period 2014-2015. Only land pixels recording at least $80 \%$ in low cloud fraction are considered for spatial average. Error bars indicate the interquartile ranges 


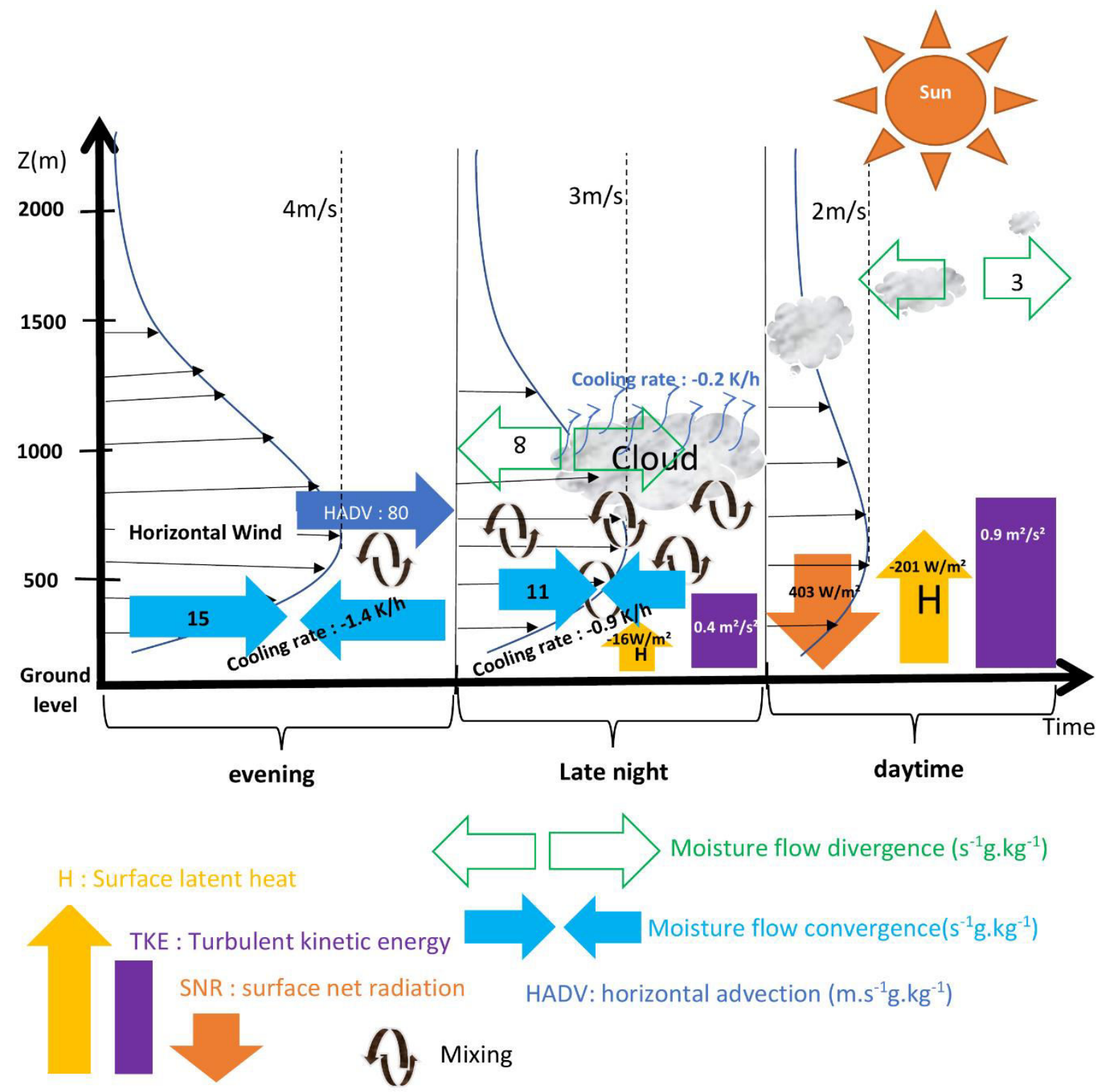

Fig. 13 Conceptual schematic model illustrating the cloud formation and dissipation processes over WCA along the diurnal cycle. The dark blue lines represent the vertical profiles of the horizontal wind with an indication of its maximum value at evening (19, 22 LT), late night $(01,04,07$ LT) and daytime $(10,13,16$ LT). The dark curled arrows symbolize mixing due to nocturnal turbulence. Maximum values for the contribution of each process are given. Each value is obtained from ERA5 within $6^{\circ} \mathrm{S}-5^{\circ} \mathrm{N} / 8^{\circ} \mathrm{E}-15^{\circ} \mathrm{E}$ for the period 2014-2015 
Declarations

949 Funding : no funding

950 Conflicts of interest: The authors declare that they have no conflicts of interest.

951 Data avaibility: The data used in this study are available on ECMWF website

952 (https://cds.climate.copernicus.eu/cdsapp\#!/dataset) for ERA5 reanalysis.

953 Terra and Aqua data can be found respectively at

954 https://ladsweb.modaps.eosdis.nasa.gov/archive/allData/61/MOD08_D3/ and

955 https://ladsweb.modaps.eosdis.nasa.gov/archive/allData/61/MYD08_D3/ and EECRA data

956 can be downloaded via https://rda.ucar.edu/datasets/ds292.2/index.html\#!sfol-wl-

$957 \quad$ /data/ds292.2

958

959

960

961

962

963

964

965

966
Code availability: All the computations have been made using matlab software. The corresponding code that supports the findings of this study are available upon request from the corresponding author.

Ethics approval: Not applicable

Consent to participate: Not applicable

Consent to publication: Not applicable 